\title{
N/N Bridge Type and Substituent Effects on Chemical and Crystallographic Properties of Schiff-Base (Salen/Salphen) $\mathrm{Ni}^{\mathrm{ii}}$ Complexes
}

\author{
Cynthia S. Novoa-Ramírez ${ }^{1,+}{ }^{\dagger}$ Areli Silva-Becerril ${ }^{1,+}{ }^{\dagger}$ Fiorella L. Olivera-Venturo ${ }^{1,2}$, \\ Juan Carlos García-Ramos 1,3 (i), Marcos Flores-Alamo ${ }^{4}$ and Lena Ruiz-Azuara ${ }^{1, *}$ \\ 1 Department of Inorganic Chemistry, Faculty of Chemistry, Universidad Nacional Autónoma de México, \\ Av. Universidad 3000, Circuito Exterior S/N, Coyoacán, C.P. 04510 Ciudad de México, Mexico; \\ cynthiasinai@comunidad.unam.mx (C.S.N.-R.); aresilbec@comunidad.unam.mx (A.S.-B.); \\ fiorella.olivera@upch.pe (F.L.O.-V.); juan.carlos.garcia.ramos@uabc.edu.mx (J.C.G.-R.) \\ 2 Department of Science, Faculty of Science and Philosophy, Av. Honorio Delgado 430, \\ 15102 San Martín de Porres, Peru \\ 3 School of Health Sciences, Universidad Autónoma de Baja California, Campus Ensenada, Ensenada, \\ 21100 Baja California, Mexico \\ 4 USAII, Faculty of Chemistry, Universidad Nacional Autónoma de México, Av. Universidad 3000, \\ Circuito Exterior S/N, Coyoacán, C.P. 04510 Ciudad de México, Mexico; mfa@unam.mx \\ * Correspondence: lena@unam.mx \\ + Equal participation in this work.
}

Received: 9 June 2020; Accepted: 13 July 2020; Published: 15 July 2020

check for updates

\begin{abstract}
In total, 13 ligands R-salen ( $\mathrm{N}, \mathrm{N}^{\prime}$-bis(5-R-salicylidene)ethylenediamine (where $\mathrm{R}=\mathrm{MeO}$, $\mathrm{Me}, \mathrm{OH}, \mathrm{H}, \mathrm{Cl}, \mathrm{Br}, \mathrm{NO}_{2}$ ) and R-salphen ( $\mathrm{N}, \mathrm{N}^{\prime}$-bis(5-R-salicylidene)-1,2-phenylenediamine (where $\mathrm{R}=\mathrm{MeO}, \mathrm{Me}, \mathrm{OH}, \mathrm{H}, \mathrm{Cl}, \mathrm{Br}$ ) and their 13 nickel complexes NiRsalen and NiRsalphen were synthesized and characterized using IR (infrared) spectroscopy, mass spectrometry, elemental analysis, magnetic susceptibility, NMR (nuclear magnetic resonance), UV-vis (ultraviolet-visible) spectroscopy, cyclic voltammetry, and X-ray crystal diffraction. Previous studies have shown that all complexes have presented a square planar geometry in a solid state and as a solution (DMSO). In electrochemical studies, it was observed that in $\mathrm{N} / \mathrm{N}$ aliphatic bridge complexes, the $\mathrm{Ni}^{\mathrm{II}}$ underwent two redox reactions, which were quasi-reversible process, and the half-wave potential followed a trend depending on the ligand substituent in the 5,5'- $\mathrm{R}$ position. The electron-donor substituent-as $-\mathrm{OH}$, and $-\mathrm{CH}_{3}$ decreased the $E_{1 / 2}$ potential—favored the reductor ability of nickel. The crystals of the complexes NiMesalen, NiMeOsalen, NiMeOsalphen, and Nisalphen were obtained. It was shown that the crystal packaging corresponded to monoclinic systems in the first three cases, as well as the triclinic for Nisalphen. The Hirshfeld surface analysis showed that the packaging was favored by $\mathrm{H} \cdots \mathrm{H}$ and $\mathrm{C} \cdots \mathrm{H} / \mathrm{H} \cdots \mathrm{C}$ interactions, and $\mathrm{C}-\mathrm{H} \cdots \mathrm{O}$ hydrogen bridges when the substituent was $-\mathrm{MeO}$ and $\pi$-stacking was added to an aromatic bridge. Replacing the $\mathrm{N} / \mathrm{N}$ bridge with an aromatic ring decreased distortion in square-planar geometry where the angles $\mathrm{O}-\mathrm{Ni}-\mathrm{N}$ formed a perfect square-planar.
\end{abstract}

Keywords: nickel; Schiff bases; crystallography; Hirshfeld surface analysis

\section{Introduction}

Salen type ligands, derived from the condensation between salicylaldehyde and a primary diamine, are considered versatile ligands in coordination chemistry because the steric and electronic properties can be modulated by different amine aldehydes precursors. The metal salen complexes have been widely studied in diverse areas of chemistry. The interest lays in its easy synthesis, versatility, and kinetic 
and thermodynamic stability provided by the chelating capacity of the tetradentate ligand with $\mathrm{N}_{2} \mathrm{O}_{2}$ donor atoms. For the aforementioned reasons, such complexes not only play an important role in coordination chemistry, but in various areas such as asymmetric catalysis [1], epoxide formation [2-4], olefin hydrogenation $[5,6]$, or in polymerization reactions $[7,8]$. Moreover, they have been extensively studied in connection with metalloprotein models and, more recently, in bioinorganic chemistry. A complex of $\mathrm{Ni}^{\mathrm{II}}, \mathrm{Fe}^{\mathrm{II}}$, and $\mathrm{Cu}^{\mathrm{II}}$-salen has been synthesized as a biomimetic compound for the study of metalloenzyme active sites and their catalytic mechanism [9-12].

It is well known that the steric and electronic effect plays an important role in the reactivity of $\mathrm{M}$-salen compounds. The incorporation of electron-donor/withdrawing groups on salen skeleton allows redox potential modulation $[9,13]$ and favors certain geometries $[14,15]$ that impact the interaction with the substrates or specific recognition sites. In recent years, attention has focused on the biological properties of Schiff bases and their metal-compounds [16], showing that ligands by themselves can inhibit a carbonic anhydrase enzyme. The efficiency of these enzymes depend on the properties of the bridge N/N [16]. Several metal-salen complexes have presented different biological activities, such as an antibacterial $[17,18]$ and antiproliferative against different tumor lines [19-22]. One of the proposed mechanisms of action of these complexes with salen-type ligands is the specific interactions with DNA and RNA. Different types of damage can occur depending on the chemical reactivity of the metal complex. Mn ${ }^{\mathrm{III}}$-salen in the presence of an oxidant induces DNA cleavages [23,24], whereas Co ${ }^{\mathrm{III}}$-salen can cleave DNA under aerobic conditions [25]. $\mathrm{Co}^{\mathrm{II}}$-salen and $\mathrm{Fe}^{\mathrm{III}}$-salen bind DNA at the minor groove [26], while $\mathrm{Ni}^{\mathrm{II}}$-salen causes damage to nucleic acids, specifically causing divisions in guanine residues in the hairpin region of a single chain [27]. On the other hand, it has been reported that square coordination compounds with conjugated systems in their coordination spheres present stacking interactions with DNA [28] and G-quadruplexes. The binding affinity and selectivity of interaction with the latter is modulated by changing the substituents on the salen skeleton and modifying the nature of the $\mathrm{N} / \mathrm{N}$-bridge for the Schiff base $[29,30]$. The correct choice of the $\mathrm{N} / \mathrm{N}$ bridge plays an important role in the geometry of these compounds, as it lengthens the chain and favors octahedral geometry [31] while adding aromatic rings that favor planar-square geometry. Moreover, it increases $\pi-\pi$ interactions [32]. These type of complexes also present a square-planar geometry [33] and multiple studies have shown how the reactivity of nickel-salen complexes can modulate by the design and control of the nature of the ligands by the choice of the N/N bridge or its substituents. Therefore, in this work, we study the effect the N/N bridge has on geometry and how the half-wave potential $\left(\mathrm{E}_{1 / 2}\right)$ changes when a substitute is added. We report the structure of four Nickel complexes with tetradentate $\mathrm{N}_{2} \mathrm{O}_{2}$ ligands, analyzing the intermolecular interactions favored by the substituent and the $\mathrm{N} / \mathrm{N}$ bridge, which modify the distance of $\mathrm{Ni}-\mathrm{Ni}$ interaction found between dimers.

\section{Materials and Methods}

The experiments were carried out in ambient conditions. Nickel acetate tetrahydrate, salicylaldehyde, 2-hydroxi-5-metoxybenzaldehyde, 2-hydroxi-5-metylbenzaldehyde, 2-hydroxi-5-nitrobenzaldehyde, 2-hydroxi-5-clorobenzaldehyde, 2-hydroxi-5-bromorobenzaldehyde, and o-phenylenediamine were acquired from Sigma-Aldrich (Saint Louis, MO, USA), whereas 1,2-diaminoethane was acquired from Merck (Darmstadt, Germany.). The solvents used were acquired from Quimica Alvi (Ciudad de México, Mexico). All reactive materials were used without further purification. Elemental analysis was carried out in the Reach and Industry Support Services Unit (USAII for its Spanish abbreviations), using an EAGER 200 elemental analyzer (EAGER 200 CHNS/method, Ciudad de México, Mexico). IR (infrared) spectra were performed on a Nicolet AVATAR 320 FT-IR (Ciudad de México, Mexico) in an interval of 4000-400 $\mathrm{cm}^{-1}$. The samples incorporated onto a KBr disk in the range of 3500-500. UV-VIS (ultraviolet-visible) spectra were obtained on a Hewlett Packard $845 \times$ UV-visible system diode array spectrophotometer in a range from $250 \mathrm{~nm}$ to $800 \mathrm{~nm}$ in dimethylsulfoxide (DMSO) solutions Sigma-Aldrich (Saint Louis, MO, USA). The ${ }^{1} \mathrm{H}-\mathrm{NMR}{ }^{13} \mathrm{C}-\mathrm{NMR}$ (nuclear magnetic resonance) (Ciudad de México, Mexico), COSY (correlation spectroscopy), and HSQC (heteronuclear single 
quantum correlation) (Tables S7 and S8, Figures S21-S39, Supplementary Materials), were performed with the USAII, collected by a VARIAN VNMRS $400 \mathrm{MHz}$. Chemical shifts were reported in ppm relative to the internal TMS (tetramethylsilane) standard. The solvents used were $\mathrm{CDCl}_{3}$, Acetone- $\mathrm{d}_{6}$, DMF- $\mathrm{d}_{7}$, and DMSO- $\mathrm{d}_{6}$, all of which were acquired from Sigma-Aldrich (Saint Louis, MO, USA). Mass spectrometers were acquired in the USAII (Ciudad de México, Mexico). All of the ligands and NiRsalen were obtained using $\mathrm{FAB}^{+}$in a LECO PEGASUSIII. NMR and mass spectrometry were not obtained for NiClsalphen and NiBrsalphen due to their low solubility. Cyclic voltammetry was performed using PAR27 potentiostat/galvanostat (Ciudad de México, Mexico) with a conventional three-electrode array. Tetrabutylammonium hexafluorophosphate (Sigma-Aldrich, Saint Louis, MO, USA), served as a support electrolyte and DMSO (99.995, Sigma-Aldrich, Misuri, United State). Voltammogram were referenced with an internal adjustment using ferrocene (99.9\%, Sigma-Aldrich, Saint Louis, MO, USA).

\subsection{Abbreviation}
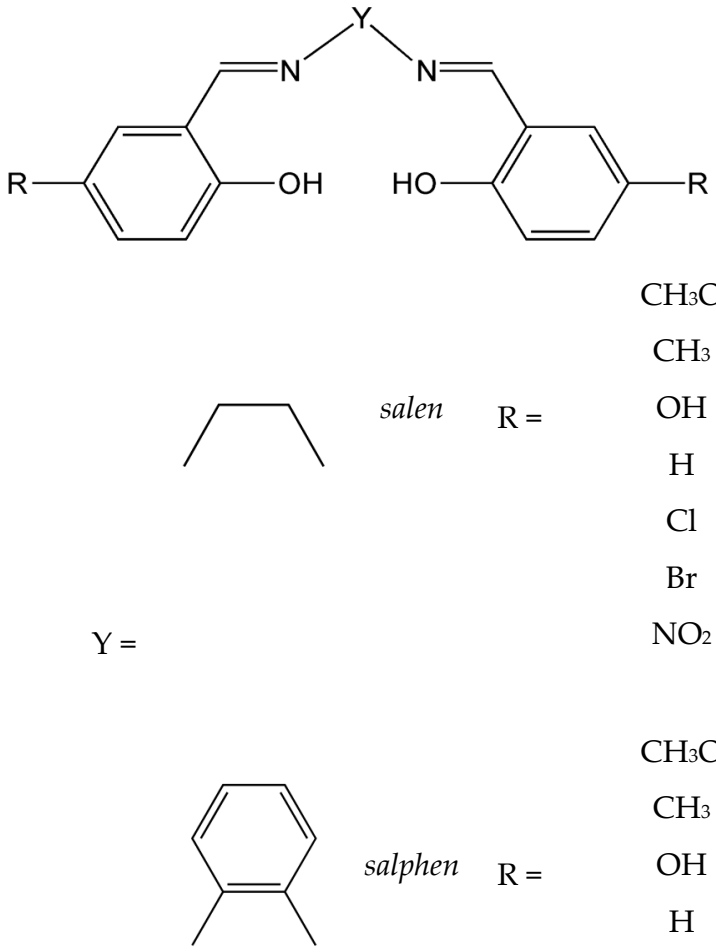

\section{$\mathrm{CH}_{3} \mathrm{O}$}

$\mathrm{CH}_{3}$

$\mathrm{OH}$

$\mathrm{H}$

$\mathrm{Cl}$

$\mathrm{Br}$

$\mathrm{NO}_{2}$

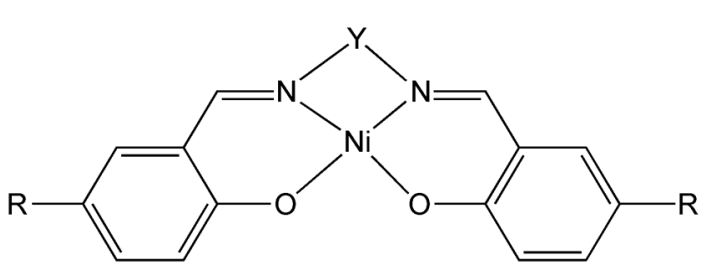

MeOsalen

Mesalen

OHsalen

Salen

Clsalen

Brsalen

$\mathrm{NO}_{2}$ salen
NiMeOsalen

NiMesalen

$\mathrm{NiOHsalen}$

Nisalen

NiClsalen

NiBrsalen

$\mathrm{Ni}$

$\mathrm{NiNO}_{2}$ salen

$\begin{array}{ccc}\mathrm{CH}_{3} \mathrm{O} & \text { MeOsalphen } & \text { NiMeOsalphen } \\ \mathrm{CH}_{3} & \text { Mesalphen } & \text { NiMesalphen } \\ \mathrm{OH} & \text { OHsalphen } & \text { NiOHsalphen } \\ \mathrm{H} & \text { Salphen } & \text { Nisalphen } \\ \mathrm{Cl} & \text { Clsalphen } & \text { NiClsalphen } \\ \mathrm{Br} & \text { Brsalphen } & \text { NiBrsalphen }\end{array}$

\subsection{Synthesis of Schiff Base Ligands}

Next, $2 \mathrm{mmol}$ of appropriate salicylaldehyde was dissolved in acetonitrile, then $1 \mathrm{mmol}$ of 1,2-diaminoethane or o-phenylenediamine was dissolved in acetonitrile and added slowly. The dissolution was stirred for $20 \mathrm{~min}$. The volume was reduced and a solid precipitated (range of yellows in the case of 1,2-diaminoethane bridge and range of orange for 0 -phenylenediamine derivatives), which was vacuum filtered and recrystallized in methanol. The ligands were characterized by elemental analysis, FT-IR spectroscopy, NMR $\left({ }^{1} \mathrm{H}\right.$ and $\left.{ }^{13} \mathrm{C}\right)$, and mass spectrometry:

MeOsalen $\mathrm{C}_{18} \mathrm{H}_{20} \mathrm{~N}_{2} \mathrm{O}_{4}$ analysis (\%Calculated (Found)): C, 65.86 (66.07); H, 6.09 (6.02); N, 8.54 (8.84). FT-IR $\left(\mathrm{cm}^{-1}\right): v C=\mathrm{N}, 1639 ; v C-\mathrm{O}, 1276$. FT-IR values were comparable to those reported [34]. $\mathrm{NMR}{ }^{1} \mathrm{H}\left(\mathrm{ppm}, \mathrm{CDCl}_{3}\right): 8.30(\mathrm{~s}, \mathrm{CH}=\mathrm{N}), 12.63\left(\mathrm{~s}, \mathrm{C}_{\mathrm{Ar}}-\mathrm{O}-\mathrm{H}\right) ;{ }^{13} \mathrm{C}(\mathrm{ppm}): 166(\mathrm{C}=\mathrm{N}), 155\left(\mathrm{C}_{\mathrm{Ar}}-\mathrm{O}\right)$. $\mathrm{M}^{+}$(m/z): 328 (328). 
Mesalen $\mathrm{C}_{18} \mathrm{H}_{20} \mathrm{~N}_{2} \mathrm{O}_{2}$ analysis (\%C(F)): C, 72.97 (73.10); H, 6.76 (6.38); N, $9.46(10.05)$. FT-IR $\left(\mathrm{cm}^{-1}\right)$ : $v \mathrm{C}=\mathrm{N}, 1637 ; v \mathrm{C}-\mathrm{O}, 1282$. FT-IR values were comparable to those reported [35]. NMR ${ }^{1} \mathrm{H}\left(\mathrm{ppm}, \mathrm{CDCl}_{3}\right)$ : $8.29(\mathrm{~s}, \mathrm{CH}=\mathrm{N}), 12.95\left(\mathrm{~s}, \mathrm{C}_{\mathrm{Ar}}-\mathrm{O}-\mathrm{H}\right) ;{ }^{13} \mathrm{C}(\mathrm{ppm}): 166(\mathrm{C}=\mathrm{N}), 159\left(\mathrm{C}_{\mathrm{Ar}}-\mathrm{O}\right) . \mathrm{M}^{+}(\mathrm{m} / \mathrm{z}): 296(296)$.

OHsalen $\mathrm{C}_{16} \mathrm{H}_{16} \mathrm{~N}_{2} \mathrm{O}_{4}$; Analysis (\%C(F)): C,63.55 (63.85); H, 5,37 (5.03); N, 9.32 (9.47). FT-IR ( $\left(\mathrm{cm}^{-1}\right)$ : $v \mathrm{C}=\mathrm{N}, 1640 ; v \mathrm{C}-\mathrm{O}, 1258$. FT-IR values were slightly lower than those reported [36]. NMR ${ }^{1} \mathrm{H}$ (ppm, Acet- $\left.\mathrm{d}_{6}\right): 8.46(\mathrm{~s}, \mathrm{CH}=\mathrm{N}), 12.40\left(\mathrm{~s}, \mathrm{C}_{\mathrm{Ar}}-\mathrm{O}-\mathrm{H}\right)$. Insoluble for NMR and mass spectrometry.

Salen $\mathrm{C}_{16} \mathrm{H}_{16} \mathrm{~N}_{2} \mathrm{O}_{2}$ analysis (\% $(\mathrm{F})$ ): $\mathrm{C}, 71.69$ (71.62); $\mathrm{H}, 5.64(6.01) ; \mathrm{N}, 10.79$ (10.44). FT-IR $\left(\mathrm{cm}^{-1}\right)$ : $v \mathrm{C}=\mathrm{N}, 1636 ; v \mathrm{C}-\mathrm{O}, 1284$. FT-IR values were comparable to those reported [37]. ${ }^{1} \mathrm{H}$ NMR (ppm, $\left.\mathrm{CDCl}_{3}\right)$ : $8.36(\mathrm{~s}, \mathrm{CH}=\mathrm{N}), 13.19\left(\mathrm{~s}, \mathrm{C}_{\mathrm{Ar}}-\mathrm{O}-\mathrm{H}\right) ;{ }^{13} \mathrm{C}(\mathrm{ppm}): 166(\mathrm{C}=\mathrm{N}), 161\left(\mathrm{C}_{\mathrm{Ar}}-\mathrm{O}\right) . \mathrm{M}^{+}(\mathrm{m} / \mathrm{z}): 268(268)$.

Clsalen $\mathrm{C}_{16} \mathrm{H}_{14} \mathrm{~N}_{2} \mathrm{Cl}_{2} \mathrm{O}_{2}$ analysis (\%C(F)): $\mathrm{C}, 56.96(57.13) ; \mathrm{H}, 4.15(3.88) ; \mathrm{N}, 8.30$ (8.52). FT-IR $\left(\mathrm{cm}^{-1}\right)$ : $v \mathrm{C}=\mathrm{N}, 1631 ; v \mathrm{C}-\mathrm{O}, 1274$. FT-IR values were slightly lower than those reported [38]. ${ }^{1} \mathrm{H}$ NMR (ppm, $\left.\mathrm{CDCl}_{3}\right): 8.29$ (s, $\left.\mathrm{CH}=\mathrm{N}\right), 13.08\left(\mathrm{~s}, \mathrm{C}_{\mathrm{Ar}}-\mathrm{O}-\mathrm{H}\right) ;{ }^{13} \mathrm{C}(\mathrm{ppm}): 165(\mathrm{C}=\mathrm{N}), 159\left(\mathrm{C}_{\mathrm{Ar}}-\mathrm{O}\right) . \mathrm{M}^{+}(\mathrm{m} / \mathrm{z}): 336$ (336).

Brsalen $\mathrm{C}_{16} \mathrm{H}_{14} \mathrm{Br}_{2} \mathrm{~N}_{2} \mathrm{O}_{2}$ analysis (\%C(F)): C, 45.07 (45.18); H, 3.29 (2.80); N, 6.57(7.22). FT-IR $\left(\mathrm{cm}^{-1}\right): v \mathrm{C}=\mathrm{N}, 1635 ; v \mathrm{C}-\mathrm{O}, 1273$. FT-IR values were comparable to those reported [34]. ${ }^{1} \mathrm{H}$ NMR (ppm, $\left.\mathrm{CDCl}_{3}\right): 8.28(\mathrm{~s}, \mathrm{CH}=\mathrm{N}), 13.10\left(\mathrm{~s}, \mathrm{C}_{\mathrm{Ar}}-\mathrm{O}-\mathrm{H}\right) ;{ }^{13} \mathrm{C}(\mathrm{ppm}): 165(\mathrm{C}=\mathrm{N}), 160\left(\mathrm{C}_{\mathrm{Ar}}-\mathrm{O}\right) . \mathrm{M}^{+}(\mathrm{m} / \mathrm{z}): 426(426)$.

$\mathrm{NO}_{2}$ salen $\mathrm{C}_{16} \mathrm{H}_{14} \mathrm{~N}_{4} \mathrm{O}_{6}$ analysis (\%C(F)): $\mathrm{C}, 53.63$ (53.69); $\mathrm{H}, 3.93$ (3.59); $\mathrm{N}, 15.63$ (15.76). FT-IR $\left(\mathrm{cm}^{-1}\right): v \mathrm{C}=\mathrm{N}, 1647 ; v \mathrm{C}-\mathrm{O}, 1326$. FT-IR values were comparable to those reported [39]. ${ }^{1} \mathrm{H}$ NMR (ppm, DMSO-d6): 8.77 (s, $\mathrm{CH}=\mathrm{N}) \cdot \mathrm{M}^{+}$(m/z): 358 (358).

MeOsalphen $\mathrm{C}_{22} \mathrm{H}_{20} \mathrm{~N}_{2} \mathrm{O}_{4}$ analysis (\%C(F)): $\mathrm{C}, 70.19$ (70.30); $\mathrm{H}, 5.35$ (5.02); N, 7.44 (7.95). FT-IR $\left(\mathrm{cm}^{-1}\right): v \mathrm{C}=\mathrm{N}, 1616 ; v \mathrm{C}-\mathrm{O}, 1275 . \quad \mathrm{NMR}{ }^{1} \mathrm{H}\left(\mathrm{ppm}\right.$, Acet-d6): $8.85(\mathrm{~s}, \mathrm{CH}=\mathrm{N}), 12.46\left(\mathrm{~s}, \mathrm{C}_{\mathrm{Ar}}-\mathrm{O}-\mathrm{H}\right)$; ${ }^{13} \mathrm{C}$ NMR (ppm): $166(\mathrm{C}=\mathrm{N}), 155\left(\mathrm{C}_{\mathrm{Ar}}-\mathrm{O}\right) . \mathrm{M}+\mathrm{H}^{+}(\mathrm{m} / \mathrm{z}): 376$ (376). The structure of this ligand was already reported [40].

Mesalphen $\mathrm{C}_{22} \mathrm{H}_{20} \mathrm{~N}_{2} \mathrm{O}_{2}$ analysis (\% $(\mathrm{F})$ ): $\mathrm{C} 76.72$ (76.83); $\mathrm{H}, 5.85(5.63) ; \mathrm{N}, 8.13(8.68)$. FT-IR ( $\mathrm{cm}^{-1}$ ): $v \mathrm{C}=\mathrm{N}, 1618 ; v \mathrm{C}-\mathrm{O}, 1283$. FT-IR values were comparable to those reported [40] $\mathrm{NMR}{ }^{1} \mathrm{H}\left(\mathrm{ppm}, \mathrm{CD}_{3} \mathrm{CN}\right)$ : $8.70(\mathrm{~s}, \mathrm{CH}=\mathrm{N}), 12.86\left(\mathrm{~s}, \mathrm{C}_{\mathrm{Ar}}-\mathrm{O}-\mathrm{H}\right) ;{ }^{13} \mathrm{C} \mathrm{NMR}(\mathrm{ppm}): 165(\mathrm{C}=\mathrm{N}), 159\left(\mathrm{C}_{\mathrm{Ar}}-\mathrm{O}\right) . \mathrm{M}+\mathrm{H}^{+}(\mathrm{m} / \mathrm{z}): 344$ (345).

OHsalphen $\mathrm{C}_{20} \mathrm{H}_{16} \mathrm{~N}_{2} \mathrm{O}_{4}$ analysis (\%C(F)): $\mathrm{C}, 68.95$ (68.96); $\mathrm{H}, 4.62$ (4.34); $\mathrm{N}, 8.04$ (8.26). FT-IR $\left(\mathrm{cm}^{-1}\right): v \mathrm{C}=\mathrm{N}, 1614 ; v \mathrm{C}-\mathrm{O}, 1277 . \mathrm{NMR}^{1} \mathrm{H}\left(\mathrm{ppm}\right.$, Acet-d6): $8.76(\mathrm{~s}, \mathrm{CH}=\mathrm{N}), 12.30\left(\mathrm{~s}, \mathrm{C}_{\mathrm{Ar}}-\mathrm{O}-\mathrm{H}\right) ;{ }^{13} \mathrm{C}$ NMR (ppm): $165(\mathrm{C}=\mathrm{N}), 155\left(\mathrm{C}_{\mathrm{Ar}}-\mathrm{O}\right) . \mathrm{M}+\mathrm{H}^{+}(\mathrm{m} / \mathrm{z}): 348$ (349).

Salphen $\mathrm{C}_{20} \mathrm{H}_{16} \mathrm{~N}_{2} \mathrm{O}_{2}$ analysis (\%C(F)): C,75.89 (75.93); $\mathrm{H}, 5.0$ (5.1); $\mathrm{N}, 8.91$ (8.85). FT-IR ( $\mathrm{cm}^{-1}$ ): $v \mathrm{C}=\mathrm{N}, 1612 ; v \mathrm{C}-\mathrm{O}, 1276$. IR values were comparable to those reported [41]. $\mathrm{M}+\mathrm{H}^{+}(\mathrm{m} / \mathrm{z}): 316$ (317). Insoluble for NMR

Clsalphen $\mathrm{C}_{20} \mathrm{H}_{14} \mathrm{~N}_{2} \mathrm{Cl}_{2} \mathrm{O}_{2}$ analysis (\%C(F)): $\mathrm{C}, 62.45$ (62.25); $\mathrm{H}, 3.66$ (3.19); $\mathrm{N}, 7.27(8.04)$. FT-IR $\left(\mathrm{cm}^{-1}\right): v \mathrm{C}=\mathrm{N}, 1614 ; v \mathrm{C}-\mathrm{O}, 1273 . \mathrm{M}+\mathrm{H}^{+}(\mathrm{m} / \mathrm{z}): 384$ (385). Insoluble for NMR. The structure of this ligand has already been reported [42].

Brsalphen $\mathrm{C}_{20} \mathrm{H}_{14} \mathrm{~N}_{2} \mathrm{Br}_{2} \mathrm{O}_{2}$ analysis (\%C(F)): $\mathrm{C}, 50.66$ (50.74); $\mathrm{H}, 2.97$ (2.57); $\mathrm{N}, 5.90$ (6.42). FT-IR $\left(\mathrm{cm}^{-1}\right): v C=\mathrm{N}, 1612 ; v C-\mathrm{O}, 1373$. FT-IR values were comparable to those reported [18]. NMR ${ }^{1} \mathrm{H}$ (ppm, Acet-d6): 8.91 (s, CH=N), 13.09 (s, $\left.\mathrm{C}_{\mathrm{Ar}}-\mathrm{O}-\mathrm{H}\right) ;{ }^{13} \mathrm{C}$ NMR $(\mathrm{ppm}): 164(\mathrm{C}=\mathrm{N}), 160\left(\mathrm{C}_{\mathrm{Ar}}-\mathrm{O}\right)$. $\mathrm{M}+\mathrm{H}^{+}(\mathrm{m} / \mathrm{z}): 474$ (474).

\subsection{Synthesis of Nickel Complexes}

In total, $1 \mathrm{mmol}$ of nickel acetate was dissolved in methanol and the ligand, previously dissolved in methanol/chloroform, was added the dropwise to the nickel acetate solution, in case the ligand $\mathrm{NO}_{2}$ salen was dissolved in the DMF (dimethylformamide). The mixture of the reaction was stirred for $15 \mathrm{~min}$ and a solid compound precipitated. In the case of the NiRsalen complex, a brown-orange precipitate was obtained. For the NiRsalphen complexes, a red solid was precipitated. The solid compound was vacuum filtered and washed with methanol and chloroform. $\mathrm{NiNO}_{2}$ salen was washed with cold DMF [43]. The compounds were characterized by elemental analysis, FT-IR spectroscopy, NMR $\left({ }^{1} \mathrm{H}\right.$ and $\left.{ }^{13} \mathrm{C}\right)$, and mass spectrometry:

NiMeOsalen, N,N'-bis(5-metoxisalicylidene)ethylenediamine, nickel(II), $\mathrm{NiC}_{18} \mathrm{H}_{18} \mathrm{~N}_{2} \mathrm{O}_{4} \cdot \mathrm{H}_{2} \mathrm{O}$ analysis (\%C(F)): C,53.63 (53.12); H, 5.00 (4.96); N, 6.95 (6.98). FT-IR $\left(\mathrm{cm}^{-1}\right)$ : vC=N, 1626; vC-O, 
1328 FT-IR values were slightly lower than those reported [34]. NMR ${ }^{1} \mathrm{H}$ (ppm, DMSO-d6): $7.80 \mathrm{~s}, \mathrm{CH}=\mathrm{N}) ;{ }^{13} \mathrm{C}(\mathrm{ppm}): 160(\mathrm{C}=\mathrm{N}), 162\left(\mathrm{C}_{\mathrm{Ar}} \mathrm{O}\right) . \mathrm{M}+\mathrm{H}^{+}(\mathrm{m} / \mathrm{z}): 384$ (385).

NiMesalen, $\mathrm{N}, \mathrm{N}^{\prime}$-bis(5-metylsalicylidene)ethylenediamine, nickel(II), $\mathrm{NiC}_{18} \mathrm{H}_{18} \mathrm{~N}_{2} \mathrm{O}_{2}$ analysis (\%C(F)): C,61.19 (61.23); H, 5.10 (5.13); N, 7.93 (7.93). FT-IR ( $\left.\mathrm{cm}^{-1}\right)$ : vC=N, 1624; vC-O, 1316 FT-IR values were comparable to those reported [35]. $\mathrm{NMR}^{1} \mathrm{H}\left(\mathrm{ppm}, \mathrm{CDCl}_{3}\right): 7.25(\mathrm{~s}, \mathrm{CH}=\mathrm{N}) ;{ }^{13} \mathrm{C}(\mathrm{ppm})$ : $161(\mathrm{C}=\mathrm{N}), 163\left(\mathrm{C}_{\mathrm{Ar}}-\mathrm{O}\right) . \mathrm{M}+\mathrm{H}^{+}(\mathrm{m} / \mathrm{z}): 352$ (353).

$\mathrm{NiOH}$ salen, $\mathrm{N}, \mathrm{N}^{\prime}$-bis(5-hidroxisalicylidene)ethylenediamine, nickel(II), $\mathrm{NiC}_{16} \mathrm{H}_{14} \mathrm{~N}_{2} \mathrm{O}_{4} \cdot 2 \mathrm{H}_{2} \mathrm{O}$ analysis (\%C(F)): C, $48.94(48.49) ; \mathrm{H}, 4.15(4.61) ; \mathrm{N}, 7.39$ (7.12). FT-IR $\left(\mathrm{cm}^{-1}\right): v \mathrm{C}=\mathrm{N}, 1614 ; v \mathrm{C}-\mathrm{O}, 1301$. NMR ${ }^{1} \mathrm{H}$ (ppm, DMSO-d6): $7.75(\mathrm{~s}, \mathrm{CH}=\mathrm{N}) ;{ }^{13} \mathrm{C}(\mathrm{ppm}): 159(\mathrm{C}=\mathrm{N}), 162\left(\mathrm{C}_{\mathrm{Ar}}-\mathrm{O}\right) . \mathrm{M}+\mathrm{H}^{+}(\mathrm{m} / \mathrm{z}): 356$ (357). The structure of this complex was already reported [44].

Nisalen, $\mathrm{N}, \mathrm{N}^{\prime}$-bis(salicylaldehyde)ethylenediamine, nickel(II), $\mathrm{NiC}_{16} \mathrm{H}_{14} \mathrm{~N}_{2} \mathrm{O}_{2}$ analysis $(\% \mathrm{C}(\mathrm{F})$ ): C, 58.77 (59.51); H, 3.89 (3.92); N, 8.57 (8.92). FT-IR ( $\left.\mathrm{cm}^{-1}\right): v \mathrm{C}=\mathrm{N}, 1624 ; v \mathrm{C}-\mathrm{O}, 1320$. NMR ${ }^{1} \mathrm{H}$ (ppm, $\left.\mathrm{CDCl}_{3}\right): 7.38(\mathrm{~s}, \mathrm{CH}=\mathrm{N}) ;{ }^{13} \mathrm{C}(\mathrm{ppm}): 162(\mathrm{C}=\mathrm{N}), 165\left(\mathrm{C}_{\mathrm{Ar}}-\mathrm{O}\right) . \mathrm{M}+\mathrm{H}^{+}(\mathrm{m} / \mathrm{z}): 324(325)$. The structure of this complex was already reported [33].

NiClsalen, $\mathrm{N}, \mathrm{N}^{\prime}$-bis(5-chlorosalicylidene)ethylenediamine, nickel(II), $\mathrm{NiC}_{16} \mathrm{H}_{12} \mathrm{~N}_{2} \mathrm{Cl}_{2} \mathrm{O}_{2} \cdot \mathrm{H}_{2} \mathrm{O}$ analysis (\%C(F)): C, 46.22 (46.22); H, $3.42(2.75) ; \mathrm{N}, 6.80$ (6.89). FT-IR $\left(\mathrm{cm}^{-1}\right): v \mathrm{C}=\mathrm{N}, 1624 ; v \mathrm{C}-\mathrm{O}$, 1312. FT-IR values were comparable to those reported [45]. $\mathrm{NMR}^{1} \mathrm{H}\left(\mathrm{ppm}, \mathrm{CDCl}_{3}\right): 7.44(\mathrm{~s}, \mathrm{CH}=\mathrm{N})$. $\mathrm{M}+\mathrm{H}^{+}(\mathrm{m} / \mathrm{z}): 394$ (394).

NiBrsalen, N,N'-bis(5-bromosalicylidene)ethylenediamine, nickel(II) $\mathrm{NiC}_{16} \mathrm{H}_{12} \mathrm{Br}_{2} \mathrm{~N}_{2} \mathrm{O}_{2} \cdot 2 \mathrm{H}_{2} \mathrm{O}$ analysis $(\% \mathrm{C}(\mathrm{F}))$ : C, $37.04(36.85) ; \mathrm{H}, 3.10(3.05) ; \mathrm{N}, 5.39(5.46)$. FT-IR $\left(\mathrm{cm}^{-1}\right)$ : vC=N, 1626; vC-O, 1309 FT-IR values are comparable to those reported [34]. NMR ${ }^{1} \mathrm{H}\left(\mathrm{ppm}, \mathrm{CDCl}_{3}\right): 7.45(\mathrm{~s}, \mathrm{CH}=\mathrm{N})$. $\mathrm{M}+\mathrm{H}^{+}(\mathrm{m} / \mathrm{z}): 482$ (483).

$\mathrm{NiNO}_{2}$ salen, $\mathrm{N}, \mathrm{N}^{\prime}$-bis(5-nitrosalicylidene)ethylenediamine), nickel(II), $\mathrm{NiC}_{16} \mathrm{H}_{12} \mathrm{~N}_{4} \mathrm{O}_{6} \cdot 1.6 \mathrm{H}_{2} \mathrm{O}$ analysis (\%C(F)): C, 42.98 (43.18); H, 3.11 (3.46); N, 12.74 (12.59). FT-IR $\left(\mathrm{cm}^{-1}\right)$ : vC=N, 1639; vC-O, 1321. FT-IR values were comparable to those reported [39]. NMR ${ }^{1} \mathrm{H}$ (ppm, DMSO-d6): 7.95 (s, CH=N). Insoluble for mass spectrometry.

NiMeOsalphen ( $\mathrm{N}, \mathrm{N}^{\prime}$-bis(5-metoxisalicylidene)-1,2-phenylenediamine, nickel(II) $\mathrm{NiC}_{22} \mathrm{H}_{18} \mathrm{~N}_{2} \mathrm{O}_{4}$ analysis (\%C(F)): C, $61.01(61.50) ; \mathrm{H}, 4.18(3.71) ; \mathrm{N}, 6.46(7.24)$. FT-IR $\left(\mathrm{cm}^{-1}\right): v \mathrm{C}=\mathrm{N}, 1616 ; v \mathrm{C}-\mathrm{O}, 1213$. $\mathrm{NMR}{ }^{1} \mathrm{H}\left(\mathrm{ppm}, \mathrm{CDCl}_{3}\right): 8.23(\mathrm{~s}, \mathrm{CH}=\mathrm{N}) . \mathrm{M}+\mathrm{H}^{+}(\mathrm{m} / \mathrm{z}): 432$ (433).

NiMesalphen, $\mathrm{N}, \mathrm{N}^{\prime}$-bis(5-metylsalicylidene)-1,2-phenylenediamine, nickel(II) $\mathrm{NiC}_{22} \mathrm{H}_{18} \mathrm{~N}_{2} \mathrm{O}_{2}$, analysis (\%C(F)): C, 65.88 (66.30); H, 4.52 (4.02); N, 6.98 (7.31). FT-IR $\left(\mathrm{cm}^{-1}\right): v \mathrm{C}=\mathrm{N}, 1624 ; v \mathrm{C}-\mathrm{O}, 1213$. $\mathrm{M}+\mathrm{H}^{+}(\mathrm{m} / \mathrm{z}): 400$ (401). Insoluble for NRM. The structure of this complex was already reported [35].

$\mathrm{NiOH}$ salphen, $\mathrm{N}, \mathrm{N}^{\prime}$-bis(5-hidroxisalicylidene)-1,2-phenylenediamine, nickel(II) $\mathrm{NiC}_{20} \mathrm{H}_{14} \mathrm{~N}_{2} \mathrm{O}_{4}$ $\mathrm{CH}_{3} \mathrm{OH}$ analysis (\%C(F)): $\mathrm{C}, 57.70(57.63) ; \mathrm{H}, 4.15(3.66) ; \mathrm{N}, 6.40(6.62)$. FT-IR $\left(\mathrm{cm}^{-1}\right)$ : $v \mathrm{C}=\mathrm{N}, 1610$; vC-O, 1220. NMR ${ }^{1} \mathrm{H}$ (ppm, DMF-7): $8.00(\mathrm{~s}, \mathrm{CH}=\mathrm{N}) ;{ }^{13} \mathrm{C}(\mathrm{ppm}): 162(\mathrm{C}=\mathrm{N}), 155\left(\mathrm{C}_{\mathrm{Ar}} \mathrm{O}\right) . \mathrm{M}+\mathrm{H}^{+}(\mathrm{m} / \mathrm{z})$ : 404 (405).

Nisalphen, $\mathrm{N}, \mathrm{N}^{\prime}$-bis(salicylaldehyde) -1,2-phenylenediamine, nickel(II) $\mathrm{NiC}_{20} \mathrm{H}_{14} \mathrm{~N}_{2} \mathrm{O}_{2}$ analysis (\%C(F)): C, 64.8 (64.4); H, 3.70(3.78); N, 7,32 (7.51). FT-IR ( $\left.\mathrm{cm}^{-1}\right)$ : vC=N, 1604; vC-O, 1295 FT-IR values were comparable to those reported [41]. $\mathrm{M}+\mathrm{H}^{+}$(m/z):372 (373). Insoluble for NRM.

NiClsalphen, $\mathrm{N}, \mathrm{N}^{\prime}$-bis(5-chlorosalicylidene)-1,2-phenylenediamine, nickel(II), $\mathrm{NiC}_{20} \mathrm{H}_{12} \mathrm{~N}_{2} \mathrm{Cl}_{2} \mathrm{O}_{2}$; analysis (\%C(F)): C, 54.35 (55.59); H, $2.73(2.28) ; \mathrm{N}, 6.33$ (7.16). FT-IR $\left(\mathrm{cm}^{-1}\right)$ : vC=N, 1608; vC-O, 1290. FT-IR values were comparable to those reported [38]. Insoluble for NRM and mass spectrometry.

NiBrsalphen, $\mathrm{N}, \mathrm{N}^{\prime}$-bis(5-bromosalicylidene)-1,2-phenylenediamine, nickel(II), $\mathrm{NiC}_{20} \mathrm{H}_{12} \mathrm{~N}_{2} \mathrm{Br}_{2} \mathrm{O}_{2}$; analysis (\%C(F)): C, 45.25 (45.77); H, 2.27 (2.16); N, 5.27 (5.87). FT-IR $\left(\mathrm{cm}^{-1}\right)$ : vC=N, 1606; vC-O, 1328. FT-IR values were comparable to those reported [18]. Insoluble for NRM and mass spectrometry.

\subsection{X-Ray Crystallography}

Suitable single crystals for compounds NiMesalen, NiMeOsalen, NiMeOsalphen, and Nisalphen were mounted on a glass fiber. Crystallographic data were collected with an Oxford Diffraction Gemini " $\mathrm{A}$ " diffractometer with a CCD area detector, with $\lambda_{\mathrm{MoK} \alpha}=0.71073 \AA$ for NiMesalen, NiMeOsalen, 
NiMeOsalphen, and $\lambda_{\mathrm{CuK} \alpha}=1.54184 \AA$ for Nisalphen at $130 \mathrm{~K}$. Unit cell parameters were determined with a set of three runs of 15 frames ( $1^{\circ}$ in $\omega$ ). The double pass method of scanning was used to exclude any noise [46]. The collected frames were integrated by using an orientation matrix determined from the narrow frame scans. Final cell constants were determined by a global refinement. Collected data were corrected for absorbance by using an analytical numeric absorption correction with a multifaceted crystal model based on expressions upon the Laue symmetry with equivalent reflections [47]. Structure solutions and refinement were carried out with the SHELXS-2014 [48] and SHELXL-2014 [49] packages. WinGX v2018.3 [50] software was used to prepare material for publication. Full-matrix least-squares refinement was carried out by minimizing $\left(F o^{2}-F c^{2}\right)^{2}$. All non-hydrogen atoms were refined anisotropically. $\mathrm{H}$ atoms attached to $\mathrm{C}$ atoms were placed in geometrically idealized positions and refined as riding on their parent atoms, with $\mathrm{C}-\mathrm{H}=0.95-0.99 \AA$ and with $U_{i s o}(\mathrm{H})=1.2 U_{e q}(\mathrm{C})$ for aromatic and methylene groups, and $1.5 U_{e q}(\mathrm{C})$ for methyl groups. On the other hand, for the compound NiMesalen, the solvent molecules were significantly disordered and could not be modeled properly (i.e., SQUEEZE [51]). Part of the PLATON package of crystallographic software was used to calculate the solvent disorder area and remove contributions to the overall intensity data. The disordered solvents area was centered around the 0.500-0.034 position and showed an estimated total of 60 electrons and a void volume of $180 \AA^{3}$. Crystallographic data for all complexes are presented in Table 1. The crystallographic data for the structures reported in this paper was deposited with the Cambridge Crystallographic Data Centre as supplementary publication no. CCDC 2006691-2006694. Copies of the data can be obtained free of charge on application to CCDC, 12 Union Road, Cambridge, CB2 1EZ, UK. (fax: (+44) 1223-336-033, e-mail: deposi@@ccdc.cam.ac.uk). 
Table 1. X-ray diffraction data collection and refinement parameters for the compounds NiMesalen, NiMeOsalen, NiMeOsalphen, and Nisalphen.

\begin{tabular}{|c|c|c|c|c|}
\hline Compound & NiMesalen & NiMeOsalen & NiMeOsalphen & Nisalphen \\
\hline $\begin{array}{l}\text { Empirical formula } \\
\text { Formula weight }\end{array}$ & $\mathrm{C}_{18} \mathrm{H}_{18} \mathrm{~N}_{2} \mathrm{Ni} \mathrm{O}_{2}$ & $\mathrm{C}_{18} \mathrm{H}_{18} \mathrm{~N}_{2} \mathrm{Ni} \mathrm{O}_{4}$ & $\mathrm{C}_{22} \mathrm{H}_{18} \mathrm{~N}_{2} \mathrm{NiO}_{4}$ & $\mathrm{C}_{43} \mathrm{H}_{31} \mathrm{C}_{19} \mathrm{~N}_{4} \mathrm{Ni}_{2} \mathrm{O}_{4}$ \\
\hline Crystal system & Monoclinic & Monoclinic & Monoclinic & Triclinic \\
\hline Space group & $C 2 / c$ & $P 21 / c$ & $P 21 / n$ & $\mathrm{P}-1$ \\
\hline \multicolumn{5}{|l|}{ Unit cell dimensions } \\
\hline $\mathrm{a}(\AA)$ & $\mathrm{a}=21.422(2)$ & $\mathrm{a}=16.5157(9)$ & $\mathrm{a}=13.5517(4)$ & $\mathrm{a}=13.7180(10)$ \\
\hline $\mathrm{b}(\AA)$ & $\mathrm{b}=13.1534(18)$ & $\mathrm{b}=7.2835(3)$ & $\mathrm{b}=7.7890(2)$ & $\mathrm{b}=14.030(2)$ \\
\hline$c(\AA)$ & $c=6.5394(6)$ & $\mathrm{c}=13.7886(7)$ & $\mathrm{c}=17.0198(4)$ & $c=14.908(2)$ \\
\hline$\alpha\left({ }^{\circ}\right)$ & $\alpha=90$ & $\alpha=90$ & $\alpha=90$ & $\alpha=115.285(12)$ \\
\hline$\beta\left({ }^{\circ}\right)$ & $\beta=96.280(9)$. & $\beta=104.809(5)$ & $\beta=100.197(3)$. & $\beta=116.477(11)$ \\
\hline $\begin{array}{l}p\left({ }^{\circ}\right) \\
\gamma\left({ }^{\circ}\right)\end{array}$ & $\begin{aligned} & \gamma=90 \\
& \beta-19\end{aligned}$ & $\begin{aligned} & \gamma=90 \\
&\gamma-0,0)\end{aligned}$ & $\gamma=90$ & $\gamma=92.967(10)$ \\
\hline Volume $\left(\AA^{3}\right)$ & $1831.6(4)$ & $1603.56(14)$ & $1768.14(8)$ & $\begin{array}{l}\text { 2215.8(5) } \\
\text { 2. }\end{array}$ \\
\hline z & 4 & 4 & 4 & 2 \\
\hline Density (calculated) $\left(\mathrm{mg} / \mathrm{m}^{3}\right)$ & 1.280 & 1.595 & 1.627 & 1.655 \\
\hline Absorption coefficient $\left(\mathrm{mm}^{-1}\right)$ & 1.068 & 1.237 & 1.880 & 1.441 \\
\hline $\mathrm{F}(000)$ & 736 & 800 & 896 & 1116 \\
\hline Crystal size $\left(\mathrm{mm}^{3}\right)$ & $0.470 \times 0.090 \times 0.070$ & $0.550 \times 0.160 \times 0.130$ & $0.470 \times 0.230 \times 0.200$ & $0.520 \times 0.170 \times 0.160$ \\
\hline Theta range for data collection & 3.641 to $29.388^{\circ}$ & 3.445 to $29.394^{\circ}$ & 3.854 to $73.599^{\circ}$ & 3.380 to $29.513^{\circ}$ \\
\hline Index ranges & $-27<=\mathrm{h}<=25,-16<=\mathrm{k}<=16,-5<=1<=9$ & $-20<=\mathrm{h}<=17,-9<=\mathrm{k}<=10,-18<=1<=19$ & $-16<=\mathrm{h}<=16,-7<=\mathrm{k}<=9,-20<=1<=19$ & $-18<=\mathrm{h}<=18,-18<=\mathrm{k}<=18,-19<=1<=16$ \\
\hline Reflections collected & 4413 & 11931 & 11435 & 18883 \\
\hline Independent reflections & $2132[\mathrm{R}(\mathrm{int})=0.0441]$ & $3921[\mathrm{R}(\mathrm{int})=0.0215]$ & $3514[\mathrm{R}(\mathrm{int})=0.0177]$ & $10314[\mathrm{R}(\mathrm{int})=0.0282]$ \\
\hline Completeness to theta $=25.242^{\circ}$ & $99.5 \%$ & $99.8 \%$ & $100.0 \%$ & $99.7 \%$ \\
\hline Absorption correction & Analytical & Analytical & Analytical & Analytical \\
\hline Max. and min. transmission & 0.929 and 0.750 & 0.854 and 0.646 & 0.725 and 0.556 & 0.827 and 0.682 \\
\hline Refinement method & Full-matrix least-squares on F2 & Full-matrix least-squares on F2 & Full-matrix least-squares on F2 & Full-matrix least-squares on F2 \\
\hline Data/restraints/parameters & $2132 / 0 / 106$ & $3921 / 0 / 228$ & $3514 / 0 / 264$ & $10314 / 0 / 559$ \\
\hline Goodness-of-fit on F2 & 1.019 & 1.047 & 1.058 & 1.027 \\
\hline Final $R$ indices $[\mathrm{I}>2$ sigma $(\mathrm{I})]$ & $\mathrm{R} 1=0.0506, \mathrm{wR} 2=0.0944$ & $\mathrm{R} 1=0.0247, \mathrm{wR} 2=0.0644$ & $\mathrm{R} 1=0.0313, \mathrm{wR} 2=0.0854$ & $\mathrm{R} 1=0.0394, \mathrm{wR} 2=0.0796$ \\
\hline $\mathrm{R}$ indices (all data) & $\mathrm{R} 1=0.0802, \mathrm{wR} 2=0.1062$ & $\mathrm{R} 1=0.0287, \mathrm{wR} 2=0.0671$ & $\mathrm{R} 1=0.0332, \mathrm{wR} 2=0.0870$ & $\mathrm{R} 1=0.0561, \mathrm{wR} 2=0.0892$ \\
\hline Largest diff. peak and hole & 0.601 and -0.625 e. $\AA-\AA$ & 0.373 and -0.344 e. $\AA$ - -3 & 0.238 and -0.567 e. $. \AA-3$ & 0.914 and -0.815 e. $\AA-\AA$ \\
\hline
\end{tabular}




\subsection{Cyclic Voltammetry}

The cyclic voltammetry was carried out with a conventional arrangement of three electrodes: a vitreous carbon working electrode, a platinum counter electrode, and a silver pseud-electrode. The potentials were referenced to the saturated calomel electrode (SCE) with ferrocene as an internal standard $\left(\mathrm{E}_{\mathrm{FC}+/ \mathrm{Fc}}^{\circ}=+0.46 \mathrm{~V}\right.$ vs. $\left.\mathrm{SCE}\right)$. The experiments were collected in $0.001 \mathrm{M}$ DMSO solutions under nitrogen atmosphere. The supporting electrolyte was $0.1 \mathrm{M}$ of tetrabutylammonium hexafluorophosphate.

\section{Results and Discussion}

\subsection{Electronic Spectra}

The electronic spectra of the Rsalen ligand showed three absorption maxima. The first was the 255-270 $\mathrm{nm}$ region and the second was the 315-350 $\mathrm{nm}$ region. These two bands were attributed to $\pi \rightarrow \pi^{*}$ transitions, with a high molar absorptivity coefficient. They also had a third band between 420-430 nm due to $\mathrm{n} \rightarrow \pi^{*}$ of the group C=N. Electronic spectra of Rsalphen were similar to Rsalen spectra. The difference was that Rsalphen spectra showed a small shoulder next to the $260 \mathrm{~nm}$ and Rsalphen ligands had another band in the 270-400 region due to the $\pi \rightarrow \pi^{*}$ transition for the third aromatic ring in $\mathrm{N} / \mathrm{N}$ bridge. All Rsalphen transitions were shifted to a major wavelength values and had bigger values of molar extinction coefficients, because the higher aromaticity of the ligands favored the delocalization of electron density.

NiRsalen showed four characteristics bands (Figures S9-S20, Supplementary Materials): the first two were in the $260-268 \mathrm{~nm}$ and $320-380 \mathrm{~nm}$ regions, with a high molar absorptivity coefficient, both due to $\pi \rightarrow \pi^{*}$ transitions of the ligand. The third ws the $405-518 \mathrm{~nm}$ due to a ligand-metal charge transfer (LMCT) transition, from the phenolate to $\mathrm{M}$ due to ${ }^{1} \mathrm{~A}_{1 \mathrm{~g}} \rightarrow{ }^{1} \mathrm{E}_{\mathrm{g}}$ transition $[52,53]$. The last band in the 500-680 $\mathrm{nm}$ region was owed to the d-d transition [52,54]. These bands could not be characterized with precision because of the low solubility of the compounds, since they presented a very low molar absorptivity coefficient. These bands were attributed to ${ }^{1} \mathrm{~A}_{1 \mathrm{~g}} \rightarrow{ }^{1} \mathrm{~A}_{2 \mathrm{~g}}$, which is characteristic for a square planar geometry. These electronic transitions were confirmed measuring the magnetic moment ( $\mu$ eff $\approx 0.5$, Table $S 6$, Supplementary Materials), meaning that the nickel complexes presented a diamagnetic property, consequences of the eight paired electrons. NiRsalphen had the same trend that their ligands and had one more $\pi \rightarrow \pi^{*}$ transition due to the third aromatic ring and higher molar extinction coefficients (Data Table 2). All maxima shifted to major wavelength values [52,54].

Table 2. Electronic spectral data of the Schiff bases and their complexes.

\begin{tabular}{|c|c|c|c|}
\hline Compound & $\lambda_{\max }\left(\varepsilon, \mathrm{L} \mathrm{mol}^{-1} \mathrm{~cm}^{-1}\right)$ in DMSO & Compound & $\lambda_{\max }\left(\varepsilon, \mathrm{L} \mathrm{mol}^{-1} \mathrm{~cm}^{-1}\right)$ in DMSO \\
\hline MeOsalen & $260,(21145), 345(14109)$ & NiMeOsalen & 258(39143), 330(7681), 431(7096) \\
\hline Mesalen & 260(17555), 326(8568), 427(176) & NiMesalen & 260(47643), 334(7975), 417(6478) \\
\hline OHsalen & 260(13265), 350(8593) & $\mathrm{NiOH} s a l e n$ & 260(40311), 333(7338), 438(6053) \\
\hline Salen & 260(8747), 327(18295), 410(299) & NiSalen & 260(58958), 324(8061), 407(5906) \\
\hline Clsalen & 258(14461), 327(7794), 420(552) & NiClsalen & 258(44337), 324(8216), 415(6263) \\
\hline Brsalen & 260(16272), 327(7479), 419(653) & NiBrsalen & 258(48523), 326(8863), 414(6419) \\
\hline $\mathrm{NO}_{2}$ salen & 258(17745), 370(20301), 422(30053) & $\mathrm{NiNO}_{2}$ salen & 263(18147), 340(11715), 405(22660) \\
\hline MeOsalphen & 276(42299), 348(18694) & NiMeOsalphen & 268(50128), 296(2969), 382(26461), 511(2355) \\
\hline Mesalphen & 274(18573), 341(14755), 450(790) & NiMesalphen & 260(55055),292(22231), 380(26821), 487(8851), 679(5.6) \\
\hline OHsalphen & 274(20172), 370(13706) & $\mathrm{NiOH}$ salphen & 260(39286), 298(19113), 386(22873), 518(8406) \\
\hline Salphen & 269(22051), 332(18444), 448(1418) & NiSalphen & 260(37709, 298(14534), 377(22632), 475(7305) \\
\hline Clsalphen & 262(18058), 275(16555), 338(8525), 398(1779) & NiClsalphen & 262(59148), 380(27100), 476(10739), 580(179) \\
\hline Brsalphen & 274(18364), 339(2102), 404(3323), 451(3341) & NiBrsalphen & 264(36210), 314(13762), 378(21675) 478(23408), 674(750) \\
\hline
\end{tabular}

The last band involved with the $\mathrm{d}-\mathrm{d}$ transition provided an approximation of the intensity of the complex field, since the energy of this electronic transition was associated with $10 \mathrm{Dq}$. This band could 
not be observed for complexes with the imine aliphatic bridge since it was masked by high intensity transitions. On the other hand, in the compounds with the aromatic bridge, we observed that those with a substituted electron-withdrawn $(-\mathrm{Br},-\mathrm{Cl})$ had a greater wavelength value, thus decreasing the energy necessary to carry out this transition, especially when compared to the substituted electron-donor $(-\mathrm{MeO},-\mathrm{OH})[43]$.

\subsection{X-Ray}

From the single crystal X-ray diffraction analysis we found that the compounds NiMesalen and NiMeOsalen of $\mathrm{Ni}^{\mathrm{II}}$ were polymorphs of $\left(2,2^{\prime}\right.$-(ethane-1,2-diylbis((nitrilo)methylylidene)) bis(4-methylphenolato))-nickel(II) methanol solvate [35] and dinuclear bis(2,2'-(ethane-1,2-diylbis ((nitrilo)methylylidene))bis(4-methoxyphenolato))-di-nickel(II) methanol solvate [35], respectively. Polymorphism was found in the crystalline arrangement, since the compound NiMesalen (Figure 1) crystallized in the monoclinic crystal system with a space group of $C 2 / c$, while in literature it was found that methanol solvated compound crystallized in the triclinic crystal system with a space group of P-1. On the other hand, NiMeOsalen crystallized in the monoclinic crystal system with a space group of $\mathrm{P} 2{ }_{1} / \mathrm{c}$, while the previously reported methanol solvated compound was space group $\mathrm{P} 2{ }_{1} / \mathrm{n}$ and monoclinic crystal system [35].

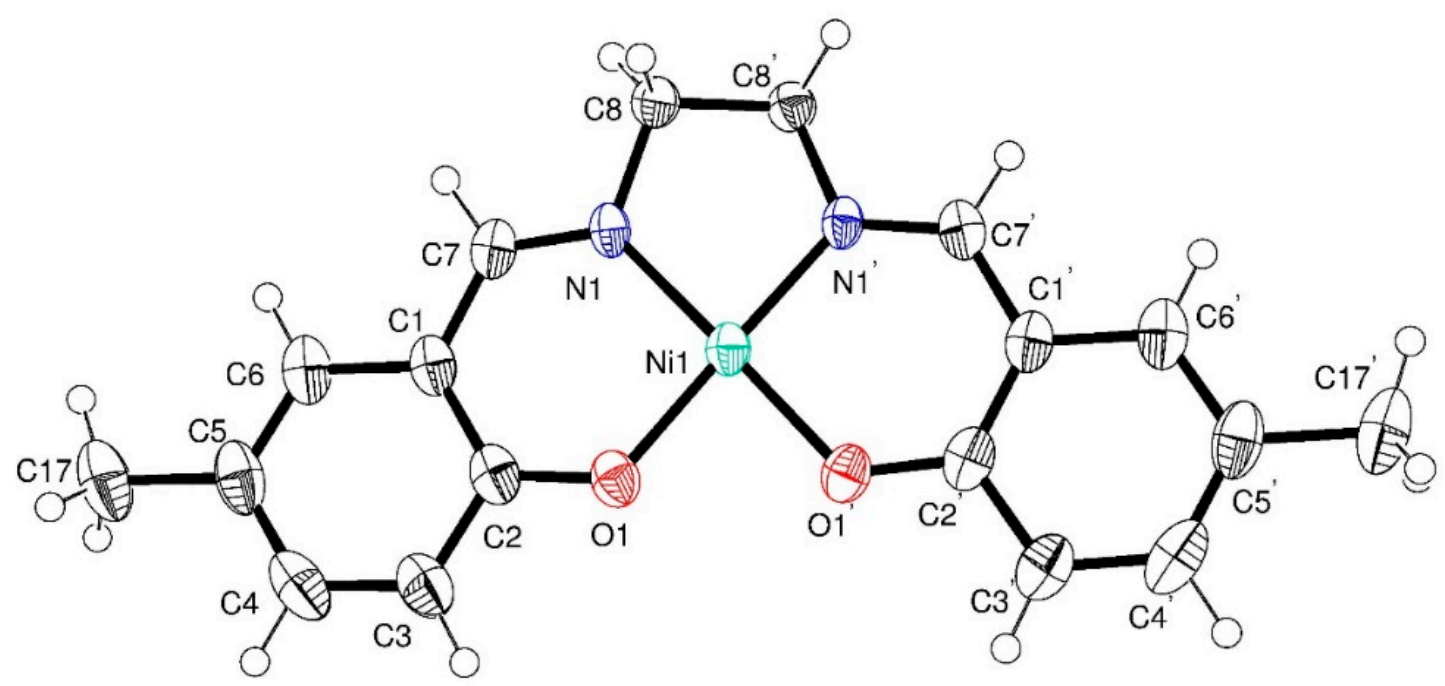

Figure 1. View on the perspective of the compound NiMesalen, with a displacement ellipsoid at a $50 \%$ probability level for non-H atoms.

Discrete unit NiMesalen contained one central $\mathrm{Ni}^{\mathrm{II}}$ ion and one unit of deprotonated 2,2'-(ethane-1,2-diylbis((nitrilo)methylylidene))bis(4-methylphenolato) tetradentate ligand. Figure 1 shows the tetracoordinated metal center of $\mathrm{Ni}^{\mathrm{II}}$ despites having a $\mathrm{N}_{2} \mathrm{O}_{2}$ coordination environment. Selected bond and angle parameters are given in Table 3.

The $\mathrm{Ni}^{\mathrm{II}}$ center had almost a perfect square-planar geometry, which was defined by two $\mathrm{N}$ and two $\mathrm{O}$ atoms with $\tau_{4}$ of 0.02 and torsion angles O1-Ni1-N1-C8 $\left(169.73(17)^{\circ}\right)$, N1'-Ni1-N1-C7 $\left(173.6(2)^{\circ}\right)$, C2-O1-Ni1-N1 $\left(7.8(2)^{\circ}\right)$, and C2-O1-Ni1-O1' $\left(171.2(2)^{\circ}\right)$. In fact, the Ni (II) atom was $0.016 \AA$ out of the plane and formed by $\mathrm{O} 1 / \mathrm{O} 1^{\prime} / \mathrm{N} 1^{\prime} / \mathrm{N} 1$. Each discrete molecule coplanar had an rms (root-mean squeare) of 0.030 . There were intermolecular interactions of type $\mathrm{C}-\mathrm{H} \cdots \mathrm{O}$, a hydrogen bond, and $\pi \cdots \pi$ contacts that stabilized the crystal packing (Figure 2). Intermolecular interactions were established as follows: the hydrogen atom $(\mathrm{C})$ carbon donor atom interacted with the $(\mathrm{O})$ oxygen acceptor atom C8-H8A...O1 (2.45 $\AA$ ), thus forming a $R_{1}^{2}(4)$ motif along the $c$ axes. In this same crystallographic direction, the interaction of type $\pi \cdots \pi$ was represented by the centroid Cg4 and six membered ring 
$\mathrm{C} 1 / \mathrm{C} 6$. The intermolecular contacts of the hydrogen bond and $\pi$-stacking array formed a bidimensional complex array along the $a-b$ plane.

Table 3. Selected bond lengths $(\AA)$ and angles $\left({ }^{\circ}\right)$ for compounds NiMesalen, NiMeOsalen, NiMeOsalphen, and Nisalphen.

\begin{tabular}{|c|c|c|c|c|c|}
\hline \multicolumn{2}{|c|}{ NiMesalen } & \multicolumn{2}{|c|}{ NiMeOsalen } & \multicolumn{2}{|c|}{ NiMeOsalphen } \\
\hline Bond * & Lengths & Bond & Lengths & Bond & Lengths \\
\hline $\mathrm{C} 2-\mathrm{O} 1$ & $1.323(3)$ & $\mathrm{C} 2-\mathrm{O} 1$ & $1.3125(17)$ & $\mathrm{C} 2-\mathrm{O} 1$ & $1.3077(18)$ \\
\hline $\mathrm{C} 5-\mathrm{C} 17$ & $1.525(4)$ & $\mathrm{C} 5-\mathrm{O} 3$ & $1.3770(17)$ & $\mathrm{C} 5-\mathrm{O} 3$ & $1.3765(18)$ \\
\hline C7-N1 & $1.297(3)$ & C7-N1 & $1.2892(19)$ & $\mathrm{C} 7-\mathrm{N} 1$ & $1.298(2)$ \\
\hline $\mathrm{C} 8-\mathrm{N} 1$ & $1.469(4)$ & $\mathrm{C} 8-\mathrm{N} 1$ & $1.4774(17)$ & $\mathrm{C} 8-\mathrm{C} 9$ & $1.397(2)$ \\
\hline $\mathrm{C} 8-\mathrm{C} 8 \# 1$ & $1.515(5)$ & $\mathrm{C} 8-\mathrm{C} 9$ & $1.504(2)$ & $\mathrm{C} 8-\mathrm{N} 1$ & $1.4233(19)$ \\
\hline $\mathrm{O} 1-\mathrm{Ni1}$ & $1.852(2)$ & $\mathrm{C} 17-\mathrm{O} 3$ & $1.4256(18)$ & $\mathrm{C} 17-\mathrm{O} 3$ & $1.4219(19)$ \\
\hline Ni1-N1\#1 & $1.844(2)$ & $\mathrm{O} 1-\mathrm{Ni1}$ & $1.8505(10)$ & $\mathrm{N} 1-\mathrm{Ni1}$ & $1.8626(12)$ \\
\hline \multirow[t]{3}{*}{ Ni1-N1 } & $1.844(2)$ & $\mathrm{O} 2-\mathrm{Ni1}$ & $1.8544(10)$ & $\mathrm{N} 2-\mathrm{Ni1}$ & $1.8643(13)$ \\
\hline & & $\mathrm{Ni1}-\mathrm{N} 2$ & $1.8476(12)$ & $\mathrm{Ni1}-\mathrm{O} 2$ & $1.8394(11)$ \\
\hline & & $\mathrm{Ni1}-\mathrm{N} 1$ & $1.8520(12)$ & $\mathrm{Ni1}-\mathrm{O} 1$ & $1.8536(11)$ \\
\hline Bond & Angles & Bond & Angles & Bond & Angles \\
\hline N1\#1-Ni1-N1 & $86.32(15)$ & $\mathrm{N} 1-\mathrm{C} 8-\mathrm{C} 9$ & $107.28(11)$ & $\mathrm{C} 9-\mathrm{C} 8-\mathrm{N} 1$ & $113.44(13)$ \\
\hline N1\#1-Ni1-O1\#1 & $94.95(9)$ & $\mathrm{N} 2-\mathrm{C} 9-\mathrm{C} 8$ & $107.04(11)$ & $\mathrm{C} 8-\mathrm{C} 9-\mathrm{N} 2$ & $114.08(13)$ \\
\hline N1-Ni1-O1\#1 & $178.40(10)$ & $\mathrm{N} 2-\mathrm{Ni1}-\mathrm{O} 1$ & 179.52(5) & $\mathrm{C} 8-\mathrm{N} 1-\mathrm{Ni1}$ & 113.37(10) \\
\hline N1\#1-Ni1-O1 & $178.40(10)$ & $\mathrm{N} 2-\mathrm{Ni1}-\mathrm{N} 1$ & $86.03(5)$ & $\mathrm{C} 9-\mathrm{N} 2-\mathrm{Ni} 1$ & 113.04(10) \\
\hline N1—Ni1-O1 & $94.95(9)$ & $\mathrm{O} 1-\mathrm{Ni1}-\mathrm{N} 1$ & $94.40(5)$ & $\mathrm{O} 2-\mathrm{Ni1}-\mathrm{O} 1$ & $84.12(5)$ \\
\hline \multirow[t]{5}{*}{$\mathrm{O} 1 \# 1-\mathrm{Ni1}-\mathrm{O} 1$} & 83.79(13) & $\mathrm{N} 2-\mathrm{Ni1}-\mathrm{O} 2$ & $93.77(5)$ & $\mathrm{O} 2-\mathrm{Ni1}-\mathrm{N} 1$ & $179.34(5)$ \\
\hline & & $\mathrm{O} 1-\mathrm{Ni1}-\mathrm{O} 2$ & $85.80(4)$ & $\mathrm{O} 1-\mathrm{Ni1}-\mathrm{N} 1$ & $95.22(5)$ \\
\hline & & $\mathrm{N} 1-\mathrm{Ni1}-\mathrm{O} 2$ & $179.60(5)$ & $\mathrm{O} 2-\mathrm{Ni1}-\mathrm{N} 2$ & $94.60(5)$ \\
\hline & & $\mathrm{C} 8-\mathrm{N} 1-\mathrm{Ni} 1$ & $114.60(9)$ & $\mathrm{O} 1-\mathrm{Ni1}-\mathrm{N} 2$ & $177.72(5)$ \\
\hline & & $\mathrm{C} 9-\mathrm{N} 2-\mathrm{Ni} 1$ & $113.22(9)$ & $\mathrm{N} 1-\mathrm{Ni1}-\mathrm{N} 2$ & $86.05(6)$ \\
\hline \multicolumn{6}{|c|}{ Nisalphen } \\
\hline \multicolumn{2}{|c|}{ Molecule A } & \multicolumn{2}{|c|}{ Molecule B } & & \\
\hline Bond * & Lengths & Bond & Lengths & & \\
\hline C2A-O1A & $1.306(3)$ & C2B-O1B & $1.306(3)$ & & \\
\hline C7A-N1A & $1.308(3)$ & C7B-N1B & $1.299(3)$ & & \\
\hline C8A-C9A & $1.395(3)$ & C8B-C9B & $1.389(4)$ & & \\
\hline C8A-N1A & $1.417(3)$ & C8B-N1B & $1.427(3)$ & & \\
\hline $\mathrm{C} 12 \mathrm{~A}-\mathrm{O} 2 \mathrm{~A}$ & $1.312(3)$ & $\mathrm{C} 12 \mathrm{~B}-\mathrm{O} 2 \mathrm{~B}$ & $1.309(3)$ & & \\
\hline O1A-Ni1A & $1.8398(16)$ & O1B-Ni1B & $1.8370(17)$ & & \\
\hline O2A-Ni1A & $1.8346(18)$ & O2B-Ni1B & $1.8360(16)$ & & \\
\hline N1A-Ni1A & $1.857(2)$ & N1B-Ni1B & $1.8567(19)$ & & \\
\hline N2A-Ni1A & $1.8564(19)$ & N2B-Ni1B & $1.856(2)$ & & \\
\hline Bond & Angles & Bond & Angles & & \\
\hline C9A-C8A-N1A & $113.8(2)$ & C9B-C8B-N1B & $113.8(2)$ & & \\
\hline C8A-C9A-N2A & $113.8(2)$ & C8B-C9B-N2B & $113.8(2)$ & & \\
\hline C8A-N1A-Ni1A & $113.13(16)$ & C8B-N1B-Ni1B & $112.87(16)$ & & \\
\hline C9A-N2A-Ni1A & $112.97(16)$ & C9B-N2B-Ni1B & $113.22(16)$ & & \\
\hline O2A-Ni1A-O1A & $83.05(8)$ & O2B-Ni1B-O1B & $83.03(7)$ & & \\
\hline O2A-Ni1A-N2A & $95.17(8)$ & O2B-Ni1B-N2B & $95.47(8)$ & & \\
\hline O1A-Ni1A-N2A & $178.13(9)$ & O1B-Ni1B-N2B & $178.47(8)$ & & \\
\hline O2A-Ni1A-N1A & $178.42(8)$ & O2B-Ni1B-N1B & $178.24(9)$ & & \\
\hline O1A-Ni1A-N1A & $95.46(8)$ & O1B-Ni1B-N1B & $95.23(8)$ & & \\
\hline N2A-Ni1A-N1A & $86.32(9)$ & N2B-Ni1B-N1B & $86.27(9)$ & & \\
\hline
\end{tabular}

* Operators for generating equivalent atoms: $-x+1, y,-z+1 / 2 \# 1$. 


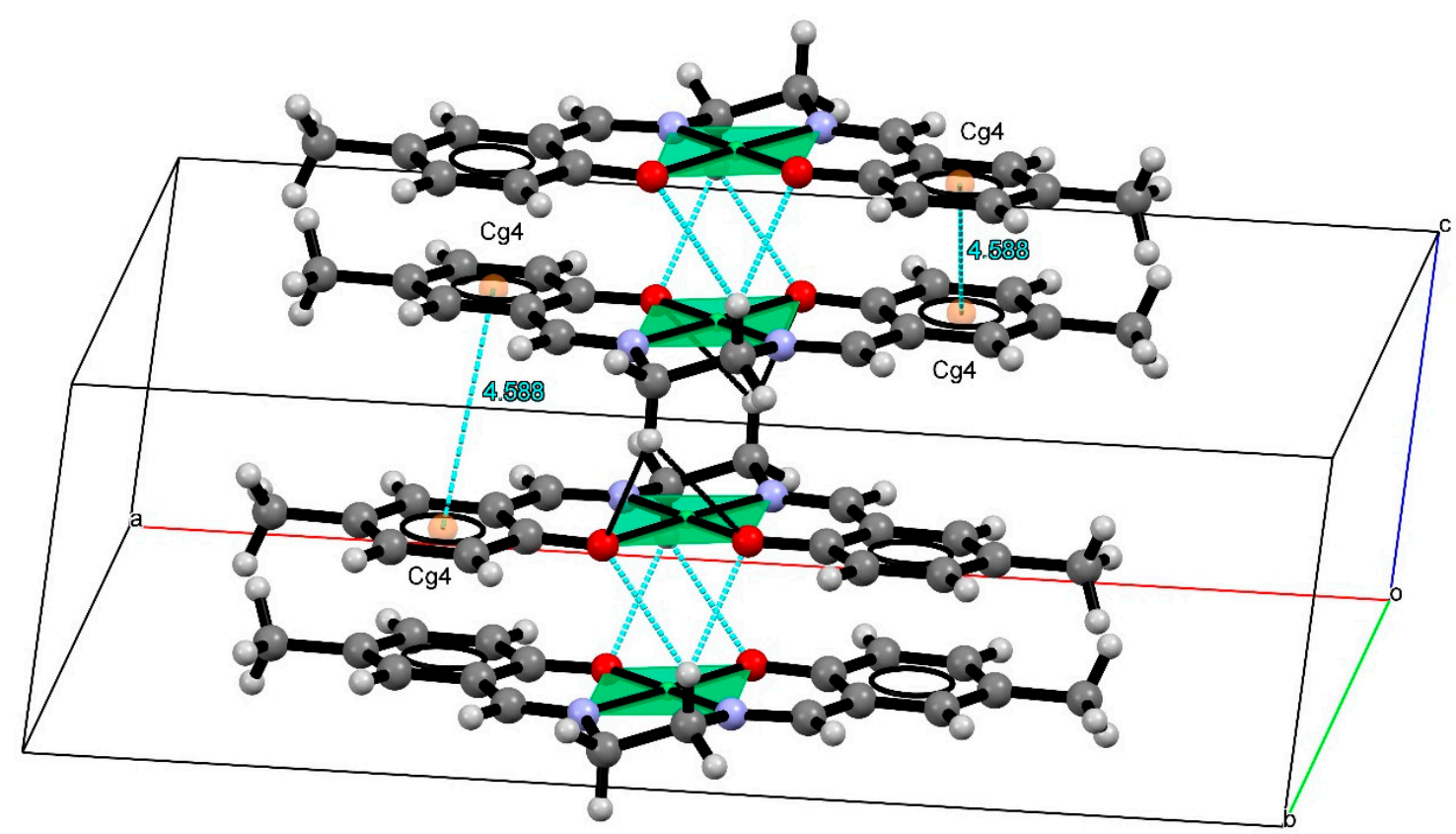

Figure 2. Crystal array of compound NiMesalen shows the view along the $b$-axis and with perspective to plane formed by $a-c$ axes emphasizing the $\pi$-stacking and $R_{2}^{1}(4)$ motif.

Figure 3 shows the perspective view of the molecular structure of polymorphic compound NiMeOsalen. The NiMeOsalen discrete unit contained one central $\mathrm{Ni}^{\mathrm{II}}$ ion and one 2,2' -(ethane-1,2-diylbis((nitrilo)methylylidene))bis(4-methoxyphenolato) tetradentate ligand. The $\mathrm{Ni}^{\mathrm{II}}$ ion was tetracoordinated with an $\mathrm{N}_{2} \mathrm{O}_{2}$ coordination environment. All bond length and angles corresponded to those reported in the literature [43]. Selected bond and angles parameters are given in Table 3.

The $\mathrm{Ni}^{\mathrm{II}}$ center had a perfect square-planar geometry, defined by two $\mathrm{N}$ and two $\mathrm{O}$ atoms with rms of $0.004, \tau_{4}$ of 0.006 , and torsion angles O1-Ni1-N1-C8 $\left(176.01(2)^{\circ}\right)$, N2-Ni1-N1-C7 $\left(176.33(2)^{\circ}\right)$, C2-O1-Ni1-N1 $\left(10.03(2)^{\circ}\right)$, and C2-O1-Ni1-O2 $\left(170.32(2)^{\circ}\right)$. In fact, the $\mathrm{Ni}^{\mathrm{II}}$ atom was $0.005 \AA$ out of the plane and formed by $\mathrm{O} 1 / \mathrm{O} 2 / \mathrm{N} 2 / \mathrm{N} 1$. Nonetheless, it was observed that the six-membered rings deviated slightly from the coplanarity, thus finding an angle of $2.60(1)^{\circ}$ between the aromatic rings.

Similarly with NiMesalen, in the crystalline arrangement for the compound NiMeOsalen, there were intermolecular interactions for the $\mathrm{C}-\mathrm{H} \cdots \mathrm{O}$ hydrogen bonding and intermolecular contacts of type $\pi \cdots \pi$ (Figure 4). For the no classical hydrogen bond, these interactions were formed between the (C) carbon

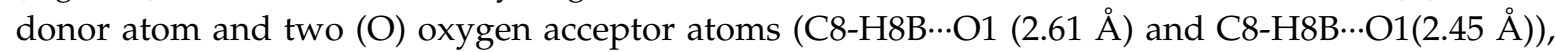

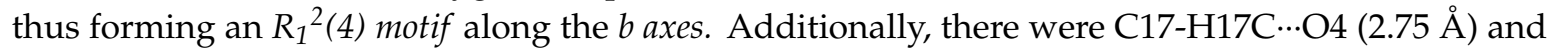
C18-H18C $\cdots \mathrm{O} 3(2.82 \AA)$, which formed an $R_{2}{ }^{2}(6)$ motif along the $b$-c plane. The weak interaction $\pi \cdots \pi$ had a distance of 3.95(8) Å between Cg4 and Cg5. Cg4 represent the six membered ring C1/C6 and Cg5 correspond to the $\mathrm{C} 11 / \mathrm{C} 16$ ring. Finally, the intermolecular contacts of no classical hydrogen bond and $\pi$-stacking formed a tridimensional supramolecular array. 


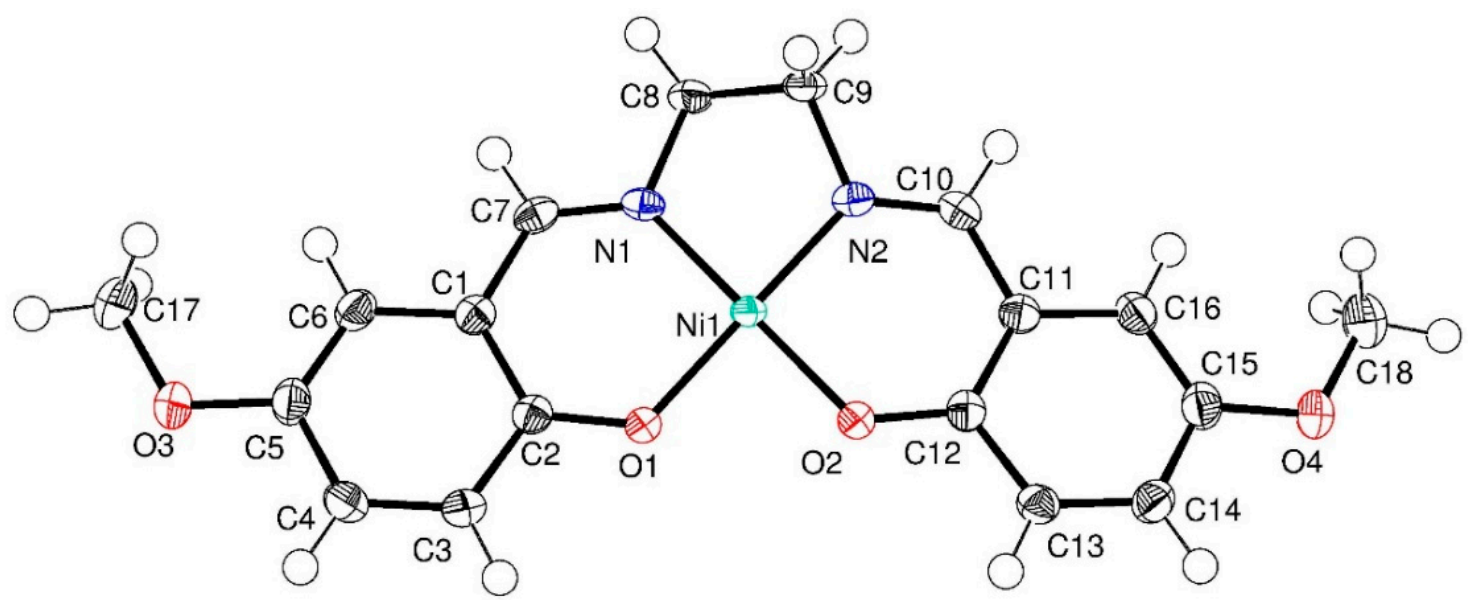

Figure 3. Perspective of the compound NiMeOsalen with a displacement ellipsoid at a $50 \%$ probability level for non-H atoms.

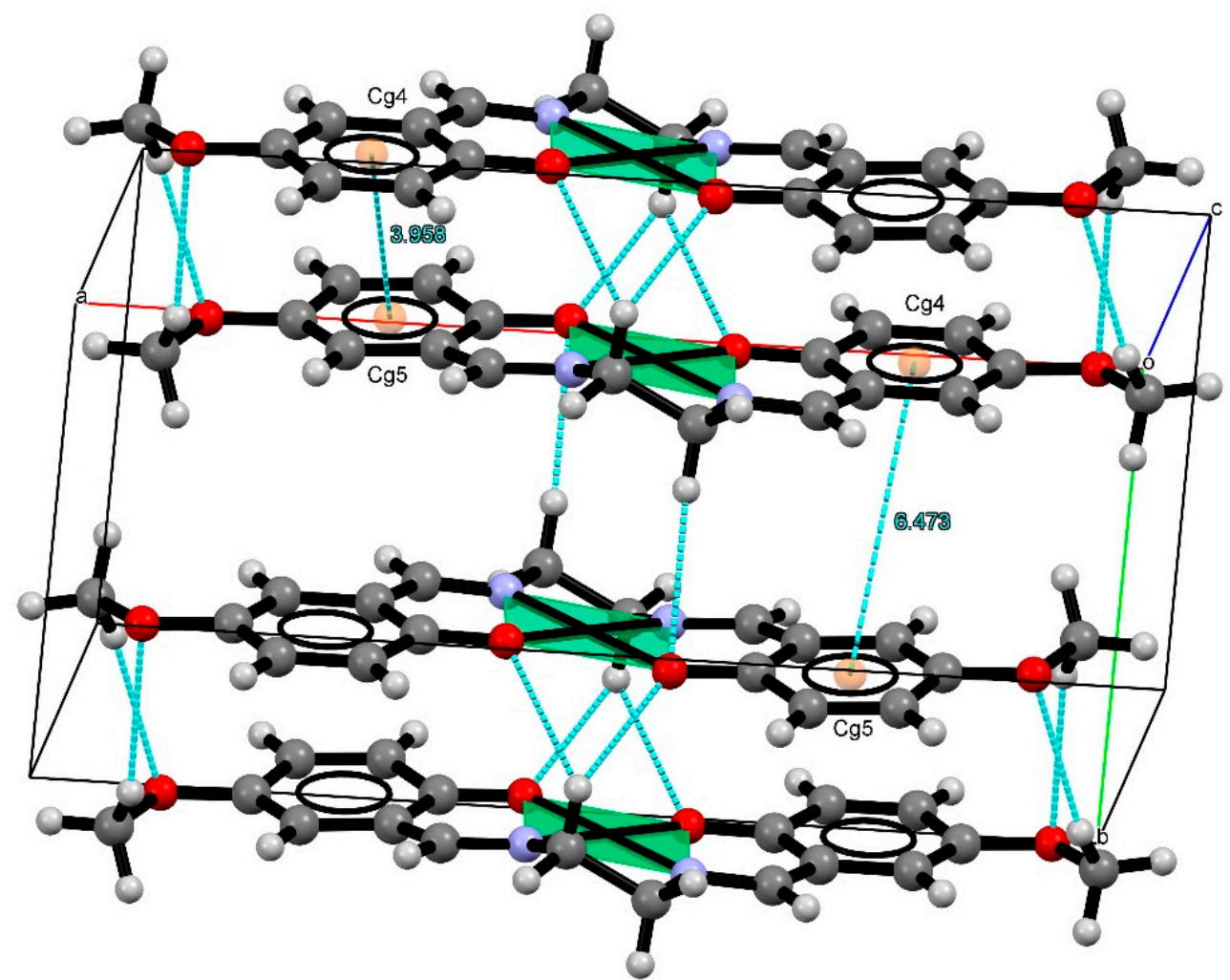

Figure 4. Crystal array of compound NiMeOsalen. View along the $c$ axes and with a perspective of a plane formed by the $a$ - $b$ axes, which emphasizes the $R_{1}^{2}(4)$ and $R_{2}^{2}(6)$ motifs, as well as $\pi$-stacking.

The compound NiMeOsalphen crystallized in a monoclinic crystal system with the space group $\mathrm{P} 21 / \mathrm{n}$. The asymmetric unit consisted of one nickel(II) center and one 2,2'-\{1,2-phenylenebis[(azanylylidene)methylylidene]\}bis(4-methoxyphenolato) ligand. The ORTEP diagram is shown in Figure 5. The squared plane of $\mathrm{Ni}^{\mathrm{II}}$ center was chelated by two oxygen and two nitrogen atoms that derived from a salen ligand, with $\mathrm{Ni}-\mathrm{O}$ and $\mathrm{Ni}-\mathrm{N}$ bond distances ranging from 1.8394 to 1.8643 (13) $\AA$. O-Ni-O, N-Ni-N, and O-Ni-N bond angles of 84.12 to $179.34^{\circ}$. The length distance of Ni-N was, on average, 1.8634(12) ̊ (Table 3), which was slightly higher than that observed in compounds NiMesalen and NiMeOsalen. Nevertheless, the tetracoordinate $\mathrm{Ni}^{\mathrm{II}}$ in compound $\mathrm{NiMeOsalphen} \mathrm{had} \mathrm{a} \mathrm{square} \mathrm{plane} \mathrm{geometry} \mathrm{with} \mathrm{a} \mathrm{rms} \mathrm{of} 0.0147$ and a $\tau_{4}$ of 0.020 . An analysis of the coplanarity shows that there were angles of $3.07(7)$ and $5.06(7)^{\circ}$ between the square plane $\mathrm{N}_{2} \mathrm{O}_{2}$ 
at the metal center. The planes formed by the six-membered rings $\mathrm{C} 1 / \mathrm{C} 6$ and $\mathrm{C} 11 / \mathrm{C} 16$, respectively. Additionally, there was a perfect coplanarity between the square plane $\mathrm{N}_{2} \mathrm{O}_{2}$ at the metal center and the ring formed by the $\mathrm{C} 8-\mathrm{C} 9-\mathrm{C} 1 / \mathrm{C} 22$ atoms with an angle of $0.52(7)^{\circ}$.

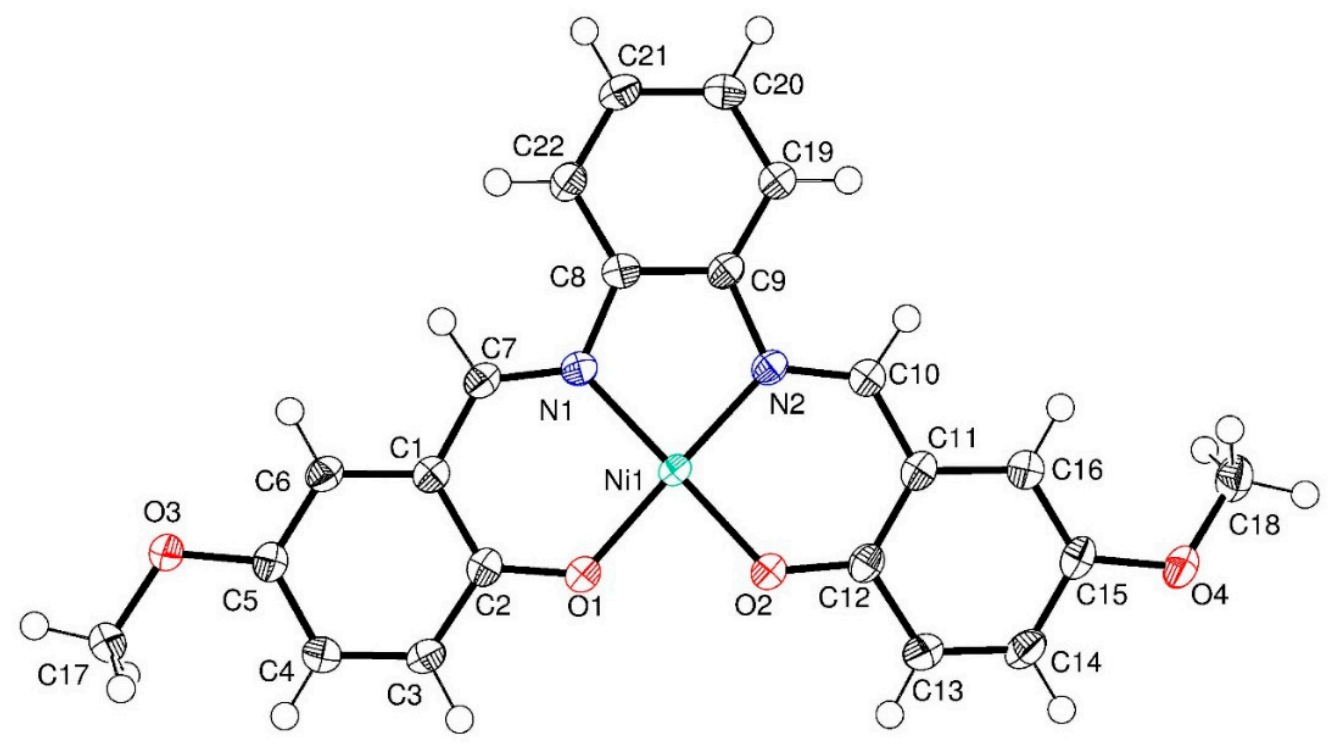

Figure 5. Perspective of the compound NiMeOsalphen with a displacement ellipsoids at a $65 \%$ probability level for non-H atoms.

In the crystal packing, there were $\mathrm{C}-\mathrm{H} \cdots \mathrm{O}$ no classic hydrogen bonds and $\pi \cdots \pi$ intermolecular contacts (Figure 6).

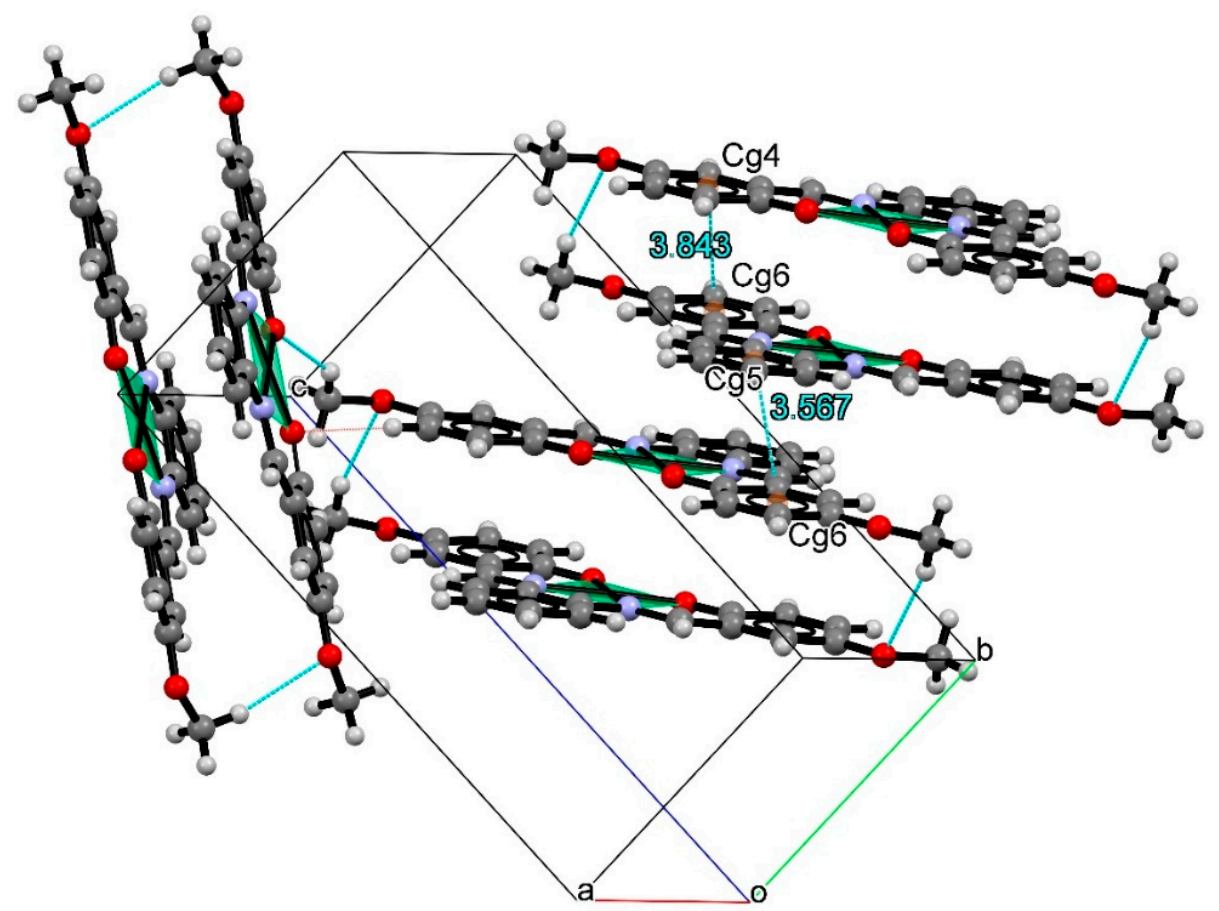

Figure 6. Crystal array of compound NiMeOsalphen. View is a tridimensional perspective emphasizing $R_{2}{ }^{2}(30)$ and $R_{2}{ }^{2}(11)$ motifs and $\pi$-stacking. 
The interactions of type hydrogen bond were observed between C17-H17C…O2 (2.43 $\mathrm{A})$,

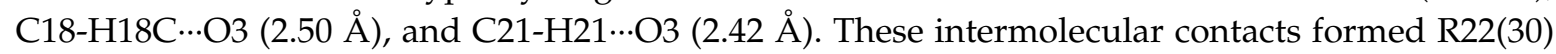
and $R_{2}{ }^{2}(11)$ motifs along the $a-c$ plane. Moreover, there were weak $\pi-\pi$ interactions with a distance of centroids Cg4-Cg6 (3.84 $\AA$ ) and Cg5-Cg6 (3.56 $)$. Cg4 represented the six membered ring C1/C6, while $\mathrm{Cg} 5$ corresponded to the $\mathrm{C} 8-\mathrm{C} 9-\mathrm{C} 19 / \mathrm{C} 22$. Cg6 was formed by the $\mathrm{C} 11 / \mathrm{C} 16$ ring. Finally, all intermolecular contacts formed a tridimensional supramolecular array.

Unlike previously mentioned compounds NiMesalen, NiMeOsalen, and NiMeOsalphen, the single crystal X-ray diffraction analysis revealed that compound Nisalphen crystalized in the triclinic space group P-1. The asymmetric unit of Nisalphen contained two molecules of the nickel coordination compound and three molecules of the chloroform, which was then used as a solvent (Figure 7). Each metal central of $\mathrm{Ni}^{\mathrm{II}}$ ion was tetracoordinated with one unit of a deprotonated salphen ligand with salphen $=\mathrm{N}, \mathrm{N}^{\prime}$-o-phenylenebis(salicylideneimine). Selected bond and angles parameters are given in Table 3.

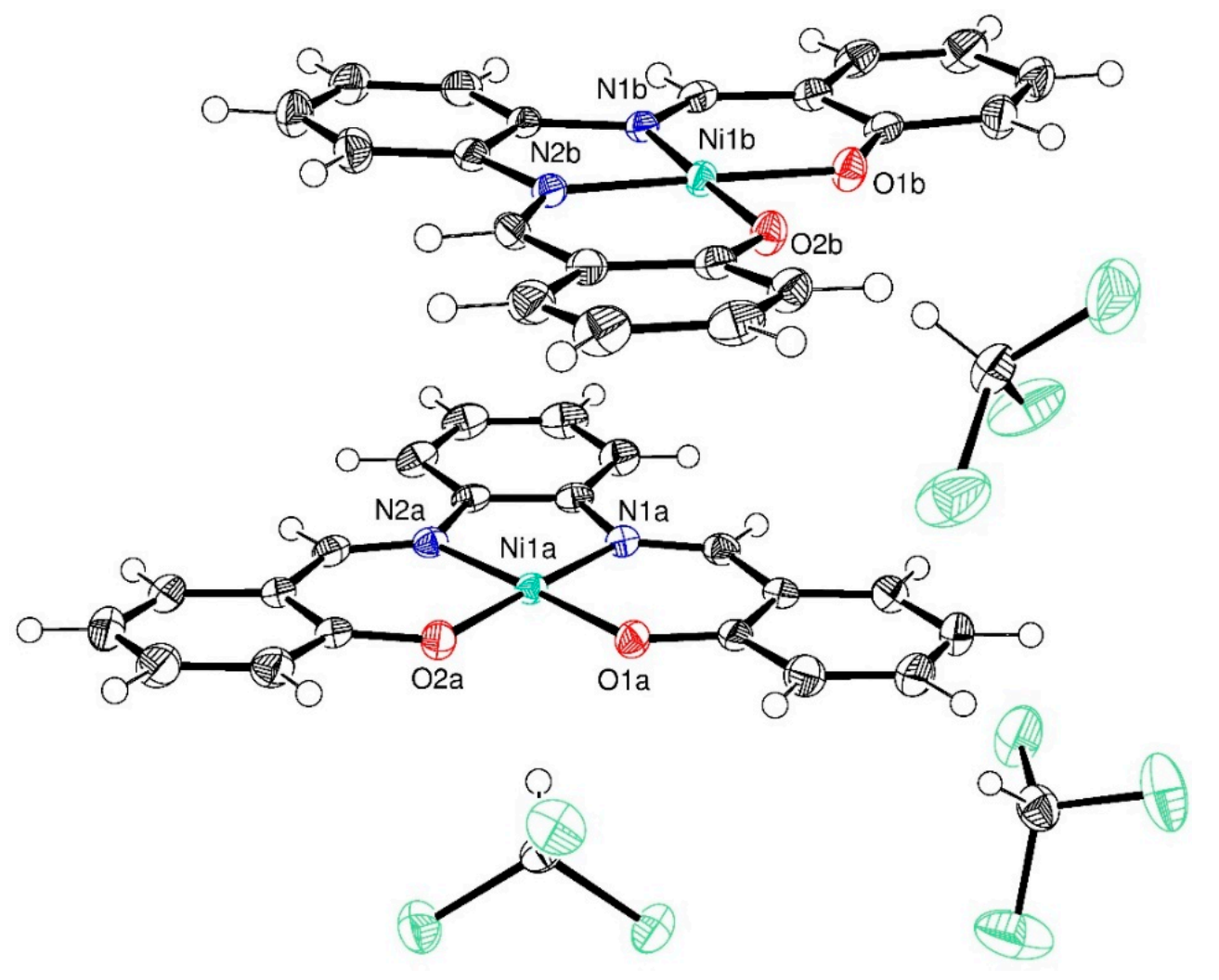

Figure 7. Perspective of the compound Nisalphen with a displacement ellipsoids at a 55\% probability level for non-H atoms.

While investigating the plane formed by three aromatic rings and the square symmetry $\mathrm{N}_{2} \mathrm{O}_{2}$ at the metallic center of $\mathrm{Ni}^{\mathrm{II}}$, we found a coplanarity in each molecule with rms of 0.060 and $0.019 \AA$ for molecules A and B, respectively. Furthermore, these molecules had a parallel arrangement between them, with an angle of $1.4^{\circ}$.

In molecule $\mathrm{A}$, there was a perfect square planar geometry with a $\tau_{4}$ de 0.026 with torsion angles O1A-Ni1A-N1A-C8A $\left(179.72(15)^{\circ}\right)$, N2A-Ni1A-N1A-C7A $\left(177.8(2)^{\circ}\right)$, C2A-O1A-Ni1A-N1A $\left(0.90(2)^{\circ}\right)$, and C2A-O1A-Ni1A-O2A $\left(179.6(2)^{\circ}\right)$. Similarly, molecule B had a perfect square planar geometry $\left(\tau_{4}\right.$ de 0.024$)$ with torsion angles O1B-Ni1B-N1B-C8B $\left(179.26(15)^{\circ}\right)$, N2B-Ni1B-N1B-C7B $\left(178.8(2)^{\circ}\right)$, C2B-O1B-Ni1B-N1B $\left(6.0(2)^{\circ}\right)$, and C2B-O1B-Ni1B-O2B $\left(173.7(2)^{\circ}\right)$.

In the crystalline arrangement of compound Nisalphen, a Ni-Ni distance of $3.26 \AA$ was observed. The short distance found between both metal centers was favored by the interaction of the $\pi \cdots \pi$. There were electronic densities in the coplanar and parllel A-A and A-B molecules. 
This system obtained dinuclear structural arrangements with possible applications in molecular modeling and bioinorganic systems. Additionally, there were intermolecular interactions for $\mathrm{C}-\mathrm{H} \cdots \mathrm{O}$ hydrogen bonding. Figure 8 shows the crystalline array with intermolecular contacts.

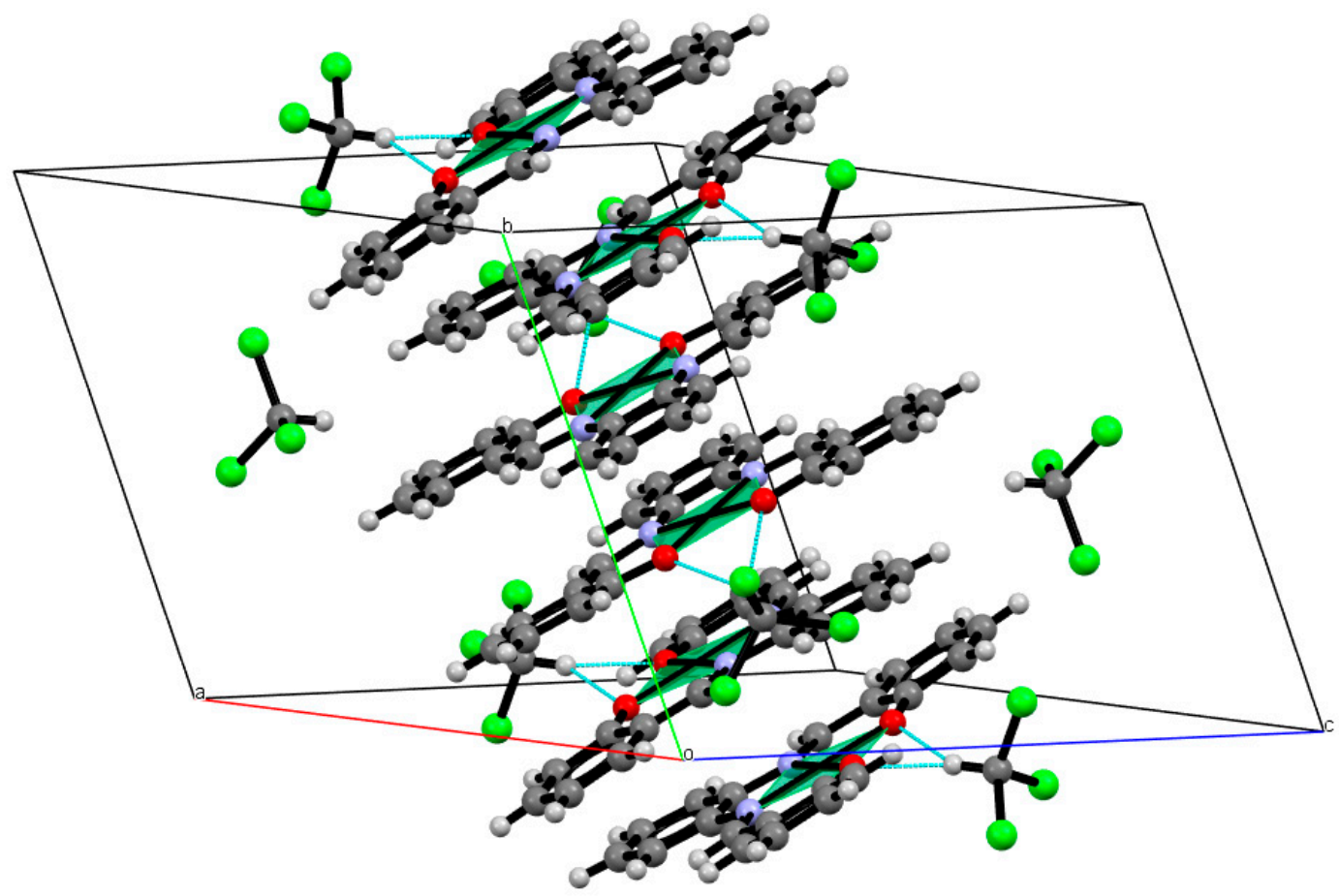

Figure 8. Crystal array of compound Nisalphen, view a tridimensional perspective emphasizing the $\pi$-stacking.

For the no classical hydrogen bond, interactions were formed between the carbon donor atom of the chloroform molecule solvent and the two oxygen acceptor atoms of the salphen ligand:

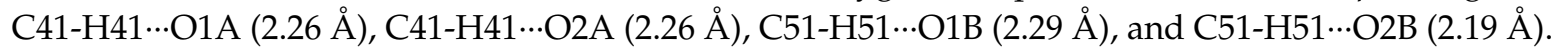
These show a linear, bifurcated, and trifurcated form for two, three, and four centers, respectively,

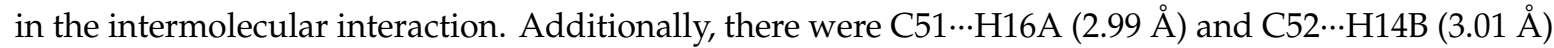
intermolecular contacts.

Despite the small differences on the $\mathrm{Ni}^{\mathrm{II}}$-donor atoms length, the nature of the $\mathrm{N} / \mathrm{N}$ bridge and electron-donor/withdrawn character of the substituents in the 5- and 5'-position of the Schiff base play a key role in packing $\mathrm{Ni}^{\mathrm{II}}$ coordination compounds. This can be observed in the Ni-Ni distance found in the different crystal structures obtained here and those previously reported.

Another important factor that influenced crystalline packing was the solvent. The Nisalen solvate reported by Siegler et al. showed a crystalline arrangement; the interactions stabilizing the crystal depended on it. It favored dimers when the $\mathrm{Ni}-\mathrm{Ni}$ distances were modified according to acetone, $3.16 \AA, \mathrm{CHCl}_{3}, 3.13 \AA$ (system monoclinic); $\mathrm{CHCl}_{3}, 3.19 \AA$ (system orthorhombic); $\mathrm{CH}_{2} \mathrm{Cl}_{2}, 3.28 \AA$; $\mathrm{C}_{2} \mathrm{H}_{4} \mathrm{O}_{2}, 3.37 \AA$; DMF, $3.3901 \AA$; or the favor 1-D chain, as was the case for the methanol solvate Ni-Ni $3.44 \AA$, wherein the solvent joined the monomers through $\mathrm{C}-\mathrm{H} \cdots \mathrm{O}$ interactions in one direction [33].

Comparing the intermolecular interactions found on Nisalen and Nisalphen, the incorporation of an extra aromatic ring in the ligand structure increased the number on the $\pi \cdots \pi$ and $\mathrm{C}-\mathrm{H} \cdots \pi$ interactions. In the two Nisalen structures reported with the same crystalline system (triclinic), the $\pi \cdots \pi$ interaction found a length of 3.63 [55] and $4.43 \AA$ [33]. Meanwhile, the two C-H $\cdots \pi$ were observed. On the other hand, the Nisalphen structure presented two $\pi \cdots \pi$ interactions with lengths of 3.89 and 4.55 and four C-H $\cdots \pi$ interactions of $3.22,3.39,3.65$, and $3.68 \AA$. The sum of all interactions led to a Ni-Ni distance of $3.26 \AA$, which was slightly smaller than the length found in both Nisalen with 3.63 and $3.36 \AA$, respectively. 
Substituents also played an important role in crystal packing. NiMeOsalphen presented three $\pi \cdots \pi$ interactions (i.e., $3.56,3.65$, and $3.84 \AA$ ), three $\mathrm{C}-\mathrm{H} \cdots \pi$ interactions $(3.24,3.33$ and $3.38 \AA$ ), and a C-H $\cdots \mathrm{O}$ interaction with a length of $2.50 \AA$. For NiMeOsalen, only one $\pi \cdots \pi$ interaction of $3.95 \AA$ was observed. There were two C-H $\cdots \pi$ interactions with lengths of 3.61 and $3.77 \AA$ and two $\mathrm{C}-\mathrm{H} \cdots \mathrm{O}$ interactions with lengths of 2.75 and $2.82 \AA$. The Ni-Ni distance observed in these examples could be closely related with the $\mathrm{C}-\mathrm{H} \cdots \mathrm{O}$ and $\pi \cdots \pi$ interactions from the methoxy groups and the extra aromatic ring for NiMeOsalphen. The Ni-Ni distance on NiMeOsalphen could be longer than $\mathrm{NiMeOsalen}$ due to the $\pi \cdots \pi$ interaction found between the two dimeric units.

For NiMesalen, the $\pi \cdots \pi$ interaction was retained but the main contribution for the crystal stabilization relied on the $\mathrm{C}-\mathrm{H} \cdots \pi$ interaction with distance values of 3.64 and $3.66 \AA$. These interactions kept the two units close enough to establish a Ni-Ni distance of $3.39 \AA$. The C-H $\cdots \mathrm{O}$ interactions elicited by the methoxy groups contributed a shorter Ni-Ni distance for NiMeOsalen (3.18 $\mathrm{A})$ than NiMesalen (3.39 ̊). The same was observed for the compounds NiMeOsalphen and NiMesalphen [35].

In the crystalline structure $\mathrm{NiOH}$ salen, two interactions of $\pi-\pi$ were shown. However, the $-\mathrm{OH}$ groups in the structure stabilized the crystalline packing mainly by the interaction of the hydrogen bridges for the $\mathrm{O}_{\text {solvent }}-\mathrm{H} \cdots \mathrm{O}_{\text {salen }}$ and $\mathrm{O}_{\text {salen }}-\mathrm{H} \cdots \mathrm{O}_{\text {solvent }}$ with methanol molecules [44]. The Ni-Ni distance was $3.61 \AA$, which, when compared to NiMeOsalen ( $3.18 \AA$ ), increased because of the sovlent's role in the packing. One methanol molecule formed a hydrogen bridge interaction with two neighboring molecules, $\mathrm{O}_{\text {solvent }}-\mathrm{H} \cdots \mathrm{O}_{\text {salen }}$ and $\mathrm{O}_{\text {salen }}-\mathrm{H} \cdots \mathrm{O}_{\text {solvent }}$ [44]. These solvent interactions also occurred in the Nisalen structure when methanol was the solvate [33].

\subsection{Hirshfeld Surface Analysis}

Hirshfeld's surface (HS) analysis provided detailed information regarding intermolecular interactions. A better understanding of the problem may help address the challenge of quantitatively understanding intermolecular contacts using visual information on color and shadow on surfaces [56].

The Crystal Explorer 17 program [57] was used to generate the HS and 2D fingerprint plots of the complexes (i.e., NiMesalen, NiMeOsalen, NiMeOsalphen, and Nisalphen). The $d_{\text {norm }}$ HS was obtained, which combined the normalized distances from the closer atom inside the surface $\left(d_{i}\right)$ and outside the surface $\left(d_{e}\right)$ to the HS, showing all contacts of the crystal structure. The red regions indicate the contacts were shorter than the sum of the van der Waals radii of the involved atoms. The blue and white regions indicated that the contacts were longer and closer to the van der Waals limit. Figure 9 shows the HS and all compound interactions.

The $d_{n o r m}$ HS of the compounds showed red spots, which indicated close-contacts in the crystal structure, i.e., non-classical hydrogen bonds $\mathrm{C}-\mathrm{H} \cdots \mathrm{O}$ and $\pi \cdots \pi$, as well as intermolecular interactions between centroids of six-membered rings in phenyl groups. The shape index was a function of HS and very helpful when investigating the $\pi \cdots \pi$ stacking interaction. The blue and red zone indicated a region with a stacking arrangement. Figure 10 presents the shape index mapped on the compounds' HS. The blue zone indicated the presence of $\pi \cdots \pi$ stacking interactions in the crystal structure. The $\pi \cdots \pi$ interaction in compound Nisalphen stabilized and favored the $3.26 \AA$ distance between the $\mathrm{Ni}^{\mathrm{II}}$ metal centers, due to the presence of molecules A and B in the asymmetric unit of Nisalphen. Figures S1-S8 present the details of the fingerprint plots for each compound. In them, they describe the intermolecular interactions around the HS.

Figure 11 shows the contributions of contacts obtained from the decomposition of the fingerprint plots. The fingerprint plots of NiMesalen, NiMeOsalen, and NiMeOsalphen were similar, indicating that the $\mathrm{H} \cdots \mathrm{H}$ and $\mathrm{C} \cdots \mathrm{H} / \mathrm{H} \cdots \mathrm{C}$ were the most important contributors for crystal packing. $\mathrm{H} \cdots \mathrm{H}$ contacts contributed $64.4 \%$ (NiMesalen), 46.4\% (NiMeOsalen), and 32.4\% (NiMeOsalphen), while C...H/H...C contacts contributed 16\% (NiMesalen), 21.2\% (NiMeOsalen), and 20\% (NiMeOsalphen). A similar trend was observed in the fingerprint plot for Nisalphen, where the $\mathrm{H} \cdots \mathrm{H}$ and $\mathrm{X} \cdots \mathrm{H} / \mathrm{H} \cdots \mathrm{X}$ contacts had greater contributors for stabilizing interactions, with $\mathrm{H} \cdots \mathrm{H}$ contacts contributing $32.5 \%$ and $27.5 \%$ in molecules $\mathrm{A}$ and $\mathrm{B}$, respectively. The contributions for $\mathrm{C} \cdots \mathrm{H} / \mathrm{H} \cdots \mathrm{C}, \mathrm{O} \cdots \mathrm{H}$, and $\mathrm{C} \cdots \mathrm{C}$ contacts were approximately 
of $20 \%, 5 \%$, and $8 \%$ for molecules $\mathrm{A}$ and $\mathrm{B}$, while the $\mathrm{Cl} \cdots \mathrm{H} / \mathrm{H} \cdots \mathrm{Cl}$ contact contributed $19.9 \%$ and $23.8 \%$ in molecules $A$ and $B$, respectively.
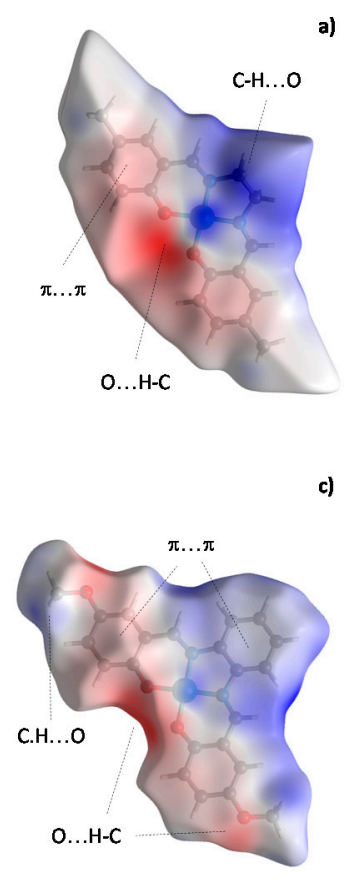

c)

a)
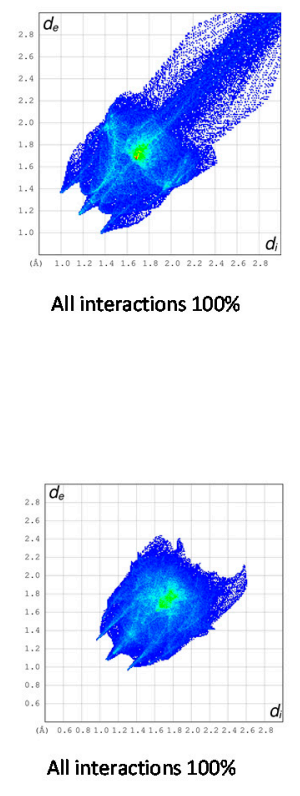

b)
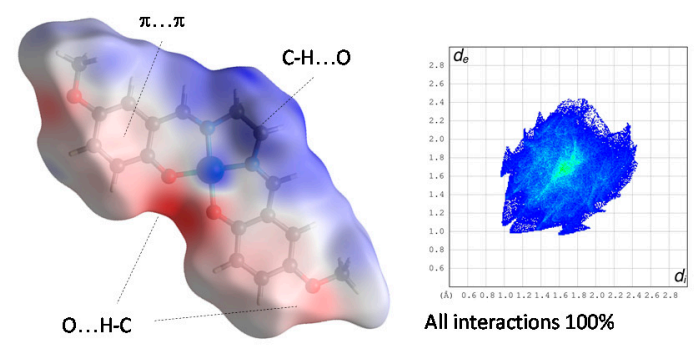

d)

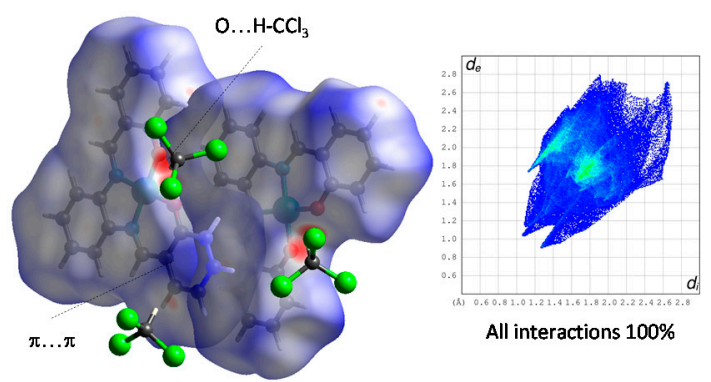

Figure 9. Hirshfeld surface (HS) with $d_{\text {norm }}$ mapped and fingerprinted plots of the compounds NiMesalen (a), NiMeOsalen (b), NiMeOsalphen (c), and Nisalphen (d) for all interactions.

a)

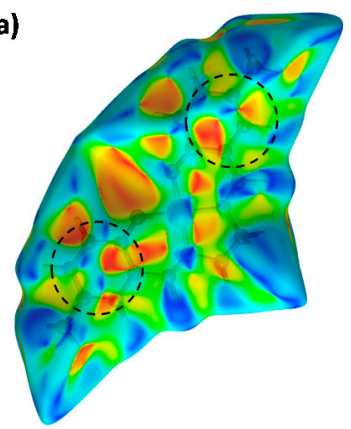

c)

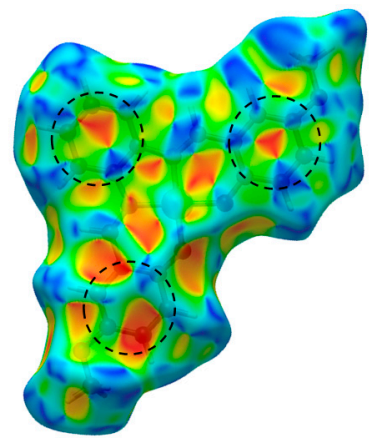

b)

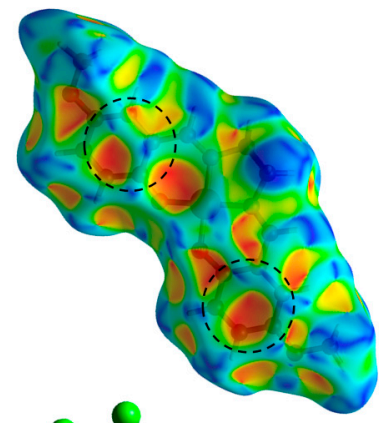

d)

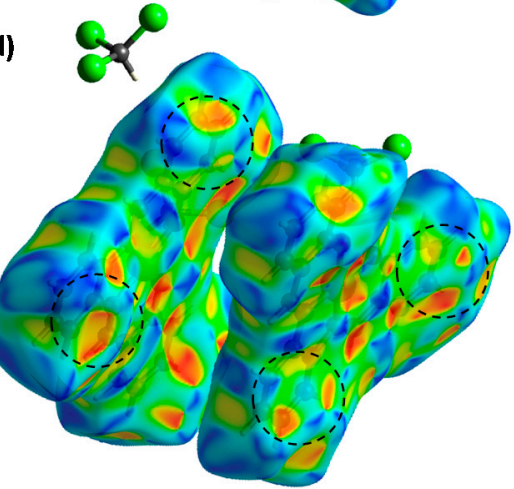

Figure 10. HS of the compounds NiMesalen (a), NiMeOsalen (b), NiMeOsalphen (c), and Nisalphen (d), mapped with shape index. 


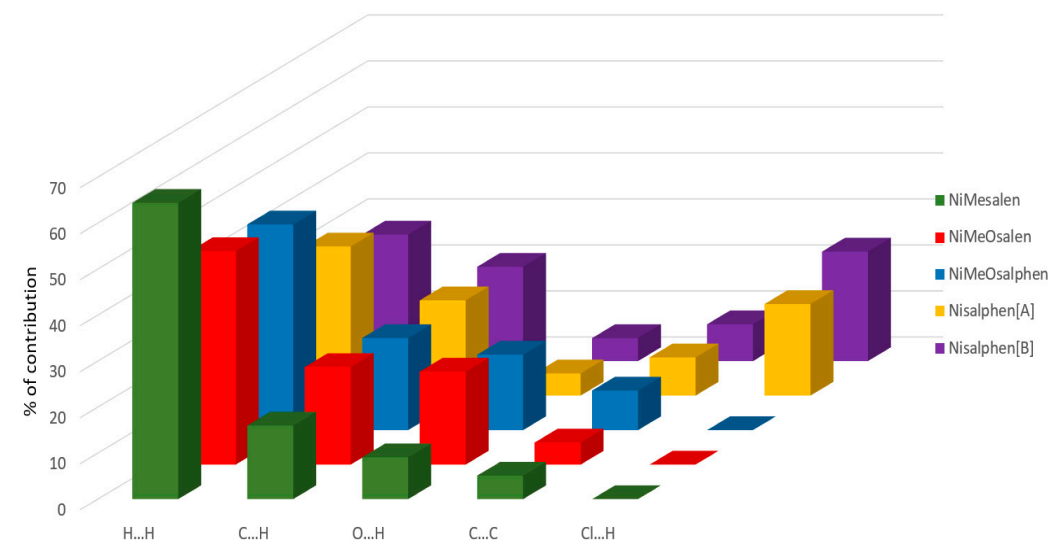

Figure 11. Contribution of some intermolecular contacts for HS of the compounds NiMesalen, NiMeOsalen, and NiMeOsalphen, as well as for molecules A and B of compound Nisalphen.

\subsection{Cyclic Voltammetry}

Nickel $^{\mathrm{II}}$-salen compounds have a neutral charge and show low solubility. Adding an extra aromatic ring in the ligand structure (i.e., salphen-type ligands) causes the solubility to decrease even more. When the NiRsalphen solution bubbled with nitrogen, it started to precipitate. Because the low solubility of the compounds, it was only possible to characterize NiRsalen compounds in the electrochemical study.

We performed voltammetry of the ligands (Figure 12b). The salen ligand ran in the direction of the positive potential in an interval of -3.2 to $1.0 \mathrm{~V}$. In an inversion study, reduction signals $3 \mathrm{a}$ and $3 \mathrm{~b}$ were associated with $\mathrm{C}=\mathrm{N}$ reduction and an irreversible oxidation signal, $4 \mathrm{a}$ [58]. Figure 12a shows the Nisalen voltammogram under the same condition, caused by the nickel oxidation process $\left(\left[\mathrm{Ni}^{\mathrm{II}} \mathrm{L}\right] \rightarrow\left[\mathrm{Ni}^{\mathrm{III}} \mathrm{L}\right]+1 \overline{\mathrm{e}}\right)$ and $2 \mathrm{a}$ and $2 \mathrm{~b}$ due to nickel reduction process $\left(\left[\mathrm{Ni}^{\mathrm{II}} \mathrm{L}\right]+1 \overline{\mathrm{e}} \rightarrow\left[\mathrm{Ni}^{\mathrm{I}} \mathrm{L}\right]\right)[14,59]$. Signal $3 \mathrm{a}$ and $3 \mathrm{~b}$ was also observed to shift lower potential values. The other NiRsalen complexes showed a similar behavior with the signals that shifted to different potentials due to the substituent in the 5,5'position (Figures S40-S46, Supplementary Materials). In this work, only the processes associated with the reduction and oxidation of nickel were reported. The voltammograms were run in an interval of -2.4 to $1.0 \mathrm{~V}$ (Figure 12c,d).

The cathodic and anodic peak current were plotted in the square root function of the sweep speed $\left(\mathrm{U}^{1 / 2}\right)$. Only the complexes $\mathrm{NiMeOH}$ salen, $\mathrm{NiOH}$ salen, $\mathrm{NiCl}$ salen, and NiBrsalen presented a linear dependence, which means that the oxidation of nickel was a diffusion-controlled process. A coupled reaction was suggested to impact the reversible process, thus confirming that Nisalen and NiMesalen via plotting $i_{\mathrm{pc}} / i_{\mathrm{pa}} \mathrm{vs}$. $\log \mathrm{V}$. The oxidation process for the complexes were irreversible due to the $\Delta \mathrm{E}$ being too big. The electron transference was a slow process, as is shown in Table 4. The oxidation process involved an $\mathrm{EC}$ mechanism and the $\mathrm{Ni}^{\mathrm{III}}$-salen complex coordinates solvents, such as DMSO, in their axial position to stabilize the $\mathrm{Ni}^{\mathrm{III}}$ oxidations for electronic density $[14,60]$.

With regard to the oxidation process, the reductions were a quasi-reversible process and we found that all nickel complex reductions were diffusion-controlled processes, except for $\mathrm{NiOHsalen,} \mathrm{which}$ presented coupled reactions. In comparation with oxidation reactions, the reduction of $\mathrm{Ni}^{\mathrm{II}}$ was a more quantitative process. $\Delta \mathrm{E}$ values were close to $59 \mathrm{mV}$ and the $i_{\mathrm{pc}} / i_{\mathrm{pa}}$ ratio was closer to 1 (Table 4 ).

For both processes, we found a trend between $E_{1 / 2}$ and the effect of the substituent. Correlations were made with the Hammett sigma in the para-position. The metal center's acidity was influenced by the effect of the substituent. Therefore, the oxidative and reductive capacity of nickel modulated with the correct use of these substituents [13,61-63]. Electron-donor substituents shifted the $E_{1 / 2}$ to a lower potential value and the electron-withdrawn groups shifted toward a more positive potential value. Thus, an electron-donor group improved the reductive capacity and electron-withdrawn groups improved the oxidative capacity of nickel, as shown in Figure 13. 

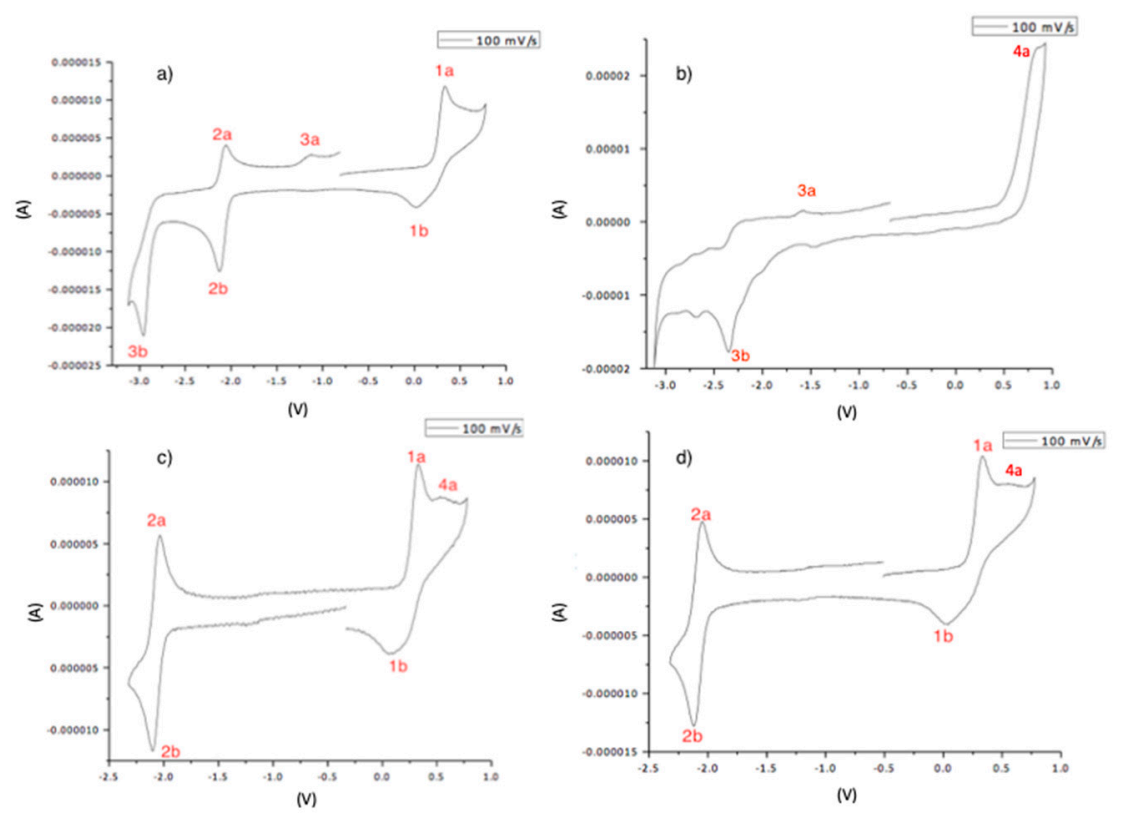

Figure 12. Voltammogram of Nisalen $1 \mathrm{mM}$ (DMSO). (a) Nisalen voltammogram from -3.2 to $1.0 \mathrm{~V}$; (b) salen voltammogram from -3.2 to $1.0 \mathrm{~V}$; (c) Nisalen voltammogram from negative potential to 2.4 to $1.0 \mathrm{~V}$; (d) Nisalen voltammogram from positive potential to -2.4 to $1.0 \mathrm{~V}$. All the experiments were referenced to the pair $\mathrm{Fc}^{+} / \mathrm{Fc}$.

Table 4. Cyclic voltammetric parameter for NiRsalen complexes, referenced to the pair $\mathrm{Fc}^{+} / \mathrm{Fc}$.

\begin{tabular}{|c|c|c|c|c|c|c|}
\hline \multirow{2}{*}{$\begin{array}{l}\text { Process } \\
\text { Compound }\end{array}$} & \multicolumn{3}{|c|}{$\mathbf{N i} i^{\mathrm{II}} \mathbf{L} \rightarrow \mathbf{N i}^{\mathrm{III}} \mathbf{L}+1 \overline{\mathbf{e}}$} & \multicolumn{3}{|c|}{$\mathbf{N i}^{\mathrm{II}} \mathbf{L}+1 \overline{\mathbf{e}} \rightarrow \mathbf{N i}^{\mathrm{I}} \mathbf{L}$} \\
\hline & $\Delta \mathrm{E}(\mathrm{mV})$ & $i_{\mathrm{pc}} / i_{\mathrm{pa}}$ & $E_{1 / 2}(\mathrm{~V})$ & $\Delta \mathrm{E}(\mathrm{mV})$ & $i_{\mathrm{pc}} / i_{\mathrm{pa}}$ & $E_{1 / 2}(\mathrm{~V})$ \\
\hline NiMeOsalen & 110 & 0.19 & 0.19 & 110 & 0.50 & -2.08 \\
\hline NiMesalen & 240 & 0.31 & 0.17 & 77 & 0.61 & -2.13 \\
\hline $\mathrm{NiOHsalen}$ & 200 & 0.12 & 0.073 & 92 & 0.30 & -2.17 \\
\hline Nisalen & 410 & 0.16 & 0.16 & 76 & 0.72 & -2.09 \\
\hline NiClsalen & 390 & 0.16 & 0.22 & 73 & 0.83 & -1.98 \\
\hline NiBrsalen & 400 & 0.23 & 0.21 & 60 & 0.45 & -1.96 \\
\hline $\mathrm{NiNO}_{2}$ salen & 200 & 0.41 & 0.33 & 120 & 0.57 & -1.72 \\
\hline
\end{tabular}

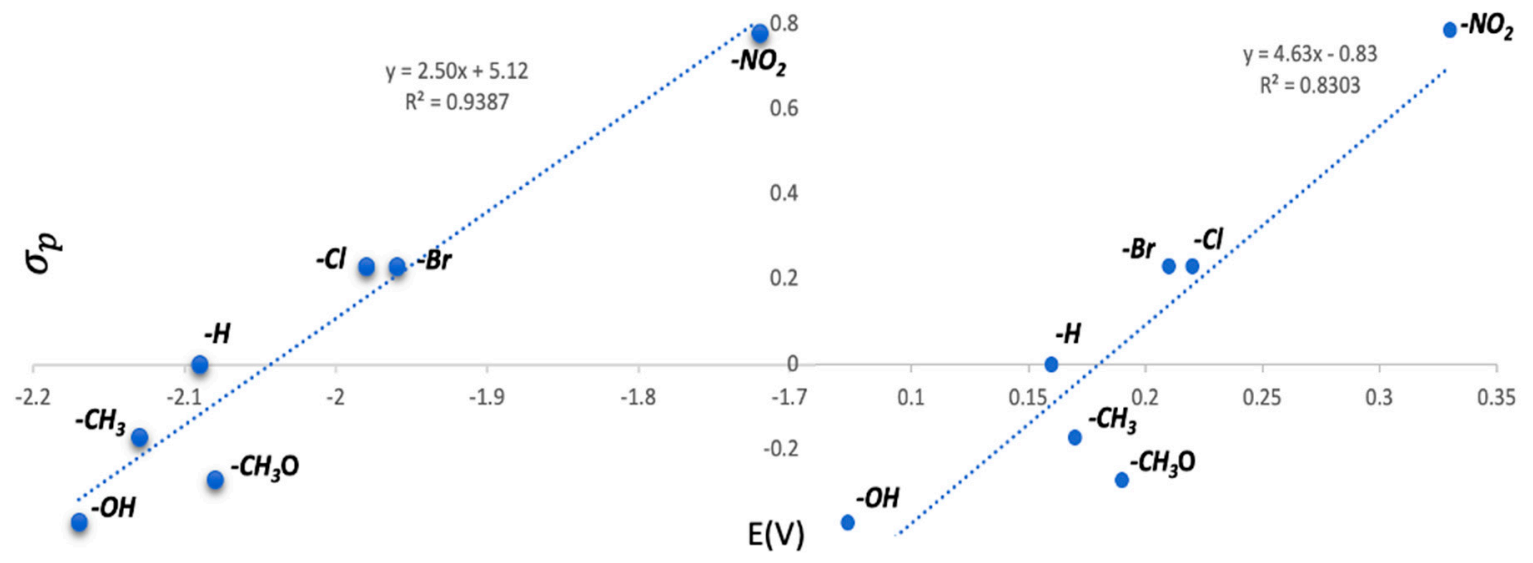

Figure 13. Left: correlation between $\mathrm{E}_{1 / 2}$ of $\mathrm{Ni}^{\mathrm{II}} / \mathrm{Ni}^{\mathrm{I}}$ and the $\sigma_{\mathrm{p}}$ constant for the NiRsalen complexes. Right: correlation between $\mathrm{E}_{1 / 2}$ of $\mathrm{Ni}^{\mathrm{III}} / \mathrm{Ni}^{\mathrm{II}}$ and the $\sigma_{\mathrm{p}}$ constant for the NiRsalen complexes. 


\section{Conclusions}

In this study, various Schiff bases and their $\mathrm{Ni}^{\mathrm{II}}$ complexes were synthesized. All the prepared ligand and complexes were analyzed via $\mathrm{C}, \mathrm{H}$, and $\mathrm{N}$ analyses. They were assigned molecular structures and geometries using information obtained from UV-Vis, magnetic susceptibility, and X-ray crystallography, all of which corresponded to square-planar geometry in the solid state. The Hirshfeld surface analysis was used to study intermolecular interactions. This analysis revealed that the $\mathrm{O} \cdots \mathrm{H}$, $\mathrm{H} \cdots \mathrm{H}$ and $\pi \cdots \pi$ contacts were the most significant in the crystal array of the compounds NiMesalen, $\mathrm{NiMeOsalen}$, and NiMeOsalphen, and $\mathrm{O} \cdots \mathrm{H}, \mathrm{H} \cdots \mathrm{H}, \mathrm{Cl} \cdots \mathrm{H}$ and $\pi \cdots \pi$ contacts in the crystal array of the compound Nisalphen. The no classical hydrogen bonding and $\pi \cdots \pi$ stacking information conveyed by Hirshfeld surface analysis were consistent with the crystal structure analysis. The substituents and the $\mathrm{N} / \mathrm{N}$ bridge affected the crystal packing and electronic properties of nickel. According to the structures obtained for Nisalphen, NiMeOsalen, and NiMeOsalphen, it was possible to observe that the addition of an aromatic ring in the $\mathrm{N} / \mathrm{N}$ bridge increased the number on $\pi \cdots \pi$ and $\mathrm{C}-\mathrm{H} \cdots \pi$ interactions and decreased their length. Substituents also played an important role in crystal packing for $\mathrm{NiMeOsalen}$ and $\mathrm{NiMeOsalphen.} \mathrm{i.e.,} \mathrm{a} \mathrm{higher} \mathrm{contribution} \mathrm{for} \mathrm{the} \mathrm{O} \cdots \mathrm{H}$ interaction. Due to this contribution, the length of $\pi \cdots \pi$ interactions were minor in both complexes. In $\mathrm{N} / \mathrm{N}$ aliphatic bridge complexes, the substituents also had an important role. The $\mathrm{E}_{1 / 2}$ depended on the electron-withdrawn or electron-donor nature of the $\mathrm{R}\left(\mathrm{R}^{\prime}\right)$ substituent, which followed a correlation with the $\sigma_{\mathrm{p}}$ of Hammet in such a way that, for the electron-donor substituent, $-\mathrm{OH}$ and $-\mathrm{CH}_{3}$ decreased the half-wave potential, instead favoring nickel's reductor ability.

Supplementary Materials: The following are available online at http://www.mdpi.com/2073-4352/10/7/616/s1, Table S1. Atomic coordinates (x 104) and equivalent isotropic displacement parameters ( 22103 ) for compound NiMesalen. $\mathrm{U}(\mathrm{eq})$ is defined as one third of the trace of the orthogonalized Uij tensor. Table S2. Atomic coordinates $(\times 104)$ and equivalent isotropic displacement parameters $(\AA 2 \times 103)$ for compound NiMeOsalen. U(eq) is defined as one third of the trace of the orthogonalized Uij tensor. Table S3. Atomic coordinates (x 104) and equivalent isotropic displacement parameters $(\AA 2 \times 103)$ for compound NiMeOsalphen. U(eq) is defined as one third of the trace of the orthogonalized Uij tensor. Table S4. Atomic coordinates $(\times 104)$ and equivalent isotropic displacement parameters $(\AA 2 \times 103)$ for compound Nisalphen. $\mathrm{U}(\mathrm{eq})$ is defined as one third of the trace of the orthogonalized Uij tensor. Table S5. Bond lengths $[\AA]$ and angles $\left[{ }^{\circ}\right]$ for compound Nisalphen. Table S6. Effective magnetic moment and number of unpaired electrons of $\mathrm{Ni}^{\mathrm{II}}$ complexes. Table S7. ${ }^{1} \mathrm{H}-\mathrm{NMR}$ values for the ligands and nickel complexes. Table S8. ${ }^{13} \mathrm{C}-\mathrm{NMR}$ values for the ligands and nickel complexes. Figure S1. Normalized contact distance $\left(\mathrm{d}_{\text {norm}}\right.$, defined in terms of $\mathrm{d}_{\mathrm{e}}, \mathrm{d}_{\mathrm{i}}$, and the van der Waals radii of the atoms) mapped on the Hirshfeld surface of the compound NiMeOsalen, represented with one surrounding moiety to visualize the intermolecular interaction. Figure S2. Hirshfeld surface with $\mathrm{d}_{\text {norm }}$ mapped and fingerprint plots for compound NiMesalen, with $\mathrm{C} \cdots \mathrm{H}$ interaction (first row) and $\mathrm{H} \cdots \mathrm{H}, \mathrm{O} \cdots \mathrm{H}$ interactions (row 2-3). The color ranges from dark blue to red with increasing frequency (relative area of the surface), corresponding to each kind of interaction. Figure S3. Normalized contact distance $\left(\mathrm{d}_{\text {norm}}\right.$, defined in terms of $\mathrm{d}_{\mathrm{e}}, \mathrm{d}_{\mathrm{i}}$, and the van der Waals radii of the atoms) mapped on the Hirshfeld surface of the compound NiMeOsalen, represented with one surrounding moiety to visualize the intermolecular interaction. Figure S4. Hirshfeld surface with $\mathrm{d}_{\text {norm }}$ mapped and fingerprint plots for NiMeOsalen, with $\mathrm{C} \cdots \mathrm{H}$ interaction (first row) and $\mathrm{H} \cdots \mathrm{H}, \mathrm{O} \cdots \mathrm{H}$ interactions (row 2-3). The color ranges from dark blue to red with increasing frequency (relative area of the surface) corresponding to each kind of interaction. Figure S5. Normalized contact distance $\left(\mathrm{d}_{\text {norm}}\right.$, defined in terms of $\mathrm{d}_{\mathrm{e}}, \mathrm{d}_{\mathrm{i}}$, and the van der Waals radii of the atoms) mapped on the Hirshfeld surface of the compound NiMeOsalphen, represented together with one surrounding moiety to visualize the intermolecular interaction. Figure $\mathrm{S} 6$. Hirshfeld surface with $\mathrm{d}_{\text {norm }}$ mapped and fingerprint plots for compound NiMeOsalphen, with $\mathrm{C} \cdots \mathrm{H}$ interaction (first row) and $\mathrm{H} \cdots \mathrm{H}, \mathrm{O} \cdots \mathrm{H}$ interactions (row 2-3). The color ranges from dark blue to red with increasing frequency (relative area of the surface) corresponding to each kind of interaction. Figure S7. Normalized contact distance $\left(\mathrm{d}_{\text {norm }}\right.$, defined in terms of $d_{e}, d_{i}$, and the van der Waals radii of the atoms) mapped on the Hirshfeld surface of the compound Nisalphen, represented together with one surrounding moiety to visualize the intermolecular interaction. Figure S8. Hirshfeld surface with $\mathrm{d}_{\text {norm }}$ mapped and fingerprint plots of the two molecules name $\mathrm{A}$ and $\mathrm{B}$ in compound Nisalphen for $\mathrm{C} \cdot \mathrm{\cdots} \mathrm{H}$ interaction (first row) and $\mathrm{H} \cdots \mathrm{H}, \mathrm{Cl} \cdots \mathrm{H}$ interactions (row 2-3). The color ranges from dark blue to red with increasing frequency (relative area of the surface) corresponding to each kind of interaction. Figure S9. UV-vis of NiMeOsalen in DMSO solution. Figure S10. UV-vis NiMesalen in DMSO solution. Figure S11. UV-vis NiOHsalen in DMSO solution. Figure S12. UV-vis of Nisalen in DMSO solution. Figure S13. UV-vis of NiClsalen in DMSO solution. Figure S14. UV-vis of NiBrsalen in DMSO solution. Figure S16. UV-vis NiMeOsalphen in DMSO solution. Figure S17. UV-vis $\mathrm{NiOH}$ salphen in DMSO solution. Figure S18. UV-vis Nisalphen in DMSO solution. Figure S19. UV-vis NiClsalphen in DMSO solution. Figure S20. UV-vis NiBrsalphen in DMSO solution. Figure S21. ${ }^{1} \mathrm{H}-\mathrm{NMR}$ of NiMeOsalen in 
DMSO-d6. Figure S22. ${ }^{13} \mathrm{C}-\mathrm{NMR}$ of NiMeOsalen in DMSO-d6. Figure S23. ${ }^{1} \mathrm{H}-\mathrm{NMR}$ of NiMesalen in chloroform. Figure S24. ${ }^{13} \mathrm{C}-\mathrm{NMR}$ of NiMesalen in chloroform. Figure S25. ${ }^{1} \mathrm{H}-\mathrm{NMR}$ of NiOHsalen in DMSO-d6. Figure S26. ${ }^{13} \mathrm{C}-\mathrm{NMR}$ of NiOHsalen in DMSO-d6. Figure S27. ${ }^{1} \mathrm{H}-\mathrm{NMR}$ of Nisalen in chloroform. Figure S28. ${ }^{13} \mathrm{C}-\mathrm{NMR}$ of Nisalen in chloroform. Figure S29. COSY spectrum of Nisalen in chloroform. Figure S30. HSQC spectrum of Nisalen in choloform. Figure S31. ${ }^{1} \mathrm{H}-\mathrm{NMR}$ of NaClsalen in chloroform. Figure S32. ${ }^{1} \mathrm{H}-\mathrm{NMR}$ of NiBrsalen in chloroform. Figure S33. ${ }^{1} \mathrm{H}-\mathrm{NMR}$ of $\mathrm{NiNO}_{2}$ salen in DMSO-d6. Figure S34. ${ }^{1} \mathrm{H}-\mathrm{NMR}$ of NiOHsalphen in DMF-d7. Figure S35. ${ }^{13} \mathrm{C}-\mathrm{NMR}$ of NiOHsalphen in DMF-d7. Figure S36. COSY spectrum of NiOHsalphen in DMF-d7. Figure S37. HSQC spectrum of NiOHsalphen in DMF-d7. Figure S38. ${ }^{1} \mathrm{H}-\mathrm{NMR}$ of NiMeOsalphen in $\mathrm{CDCl}_{3}$. Figure S39. COSY spectrum of NiMeOsalphen in $\mathrm{CDCl}_{3}$. Figure S40. Voltammogram of NiMeOsalen $1 \mathrm{mM}$ in DMSO. Figure S41. Voltammogram of NiMesalen $1 \mathrm{mM}$ in DMSO. Figure S42. Voltammogram of NiOHsalen $1 \mathrm{mM}$ in DMSO. Figure S43. Voltammogram of Nisalen $1 \mathrm{mM}$ in DMSO. Figure S44. Voltammogram of NiClsalen $1 \mathrm{mM}$ in DMSO. Figure S45. Voltammogram of NiBrsalen $1 \mathrm{mM}$ in DMSO. Figure S46. Voltammogram of $\mathrm{NiNO}_{2}$ salen $1 \mathrm{mM}$ in DMSO.

Author Contributions: Conceptualization, C.S.N.-R. and A.S.-B.; methodology, C.S.N.-R., A.S.-B., and F.L.O.-V.; software, M.F.-A.; formal analysis, C.S.N.-R., A.S.-B., J.C.G.-R., and M.F.-A.; investigation, L.R.-A.; direction and resources, L.R.-A.; data curation, M.F.-A.; writing-original draft preparation, C.S.N.-R., A.S.-B., and M.F.-A.; writing-review and editing, L.R.-A. and J.C.G.-R., supervision,. L.R.-A.; project administration, L.R.-A.; funding acquisition, L.R.-A. All authors have read and agreed to the published version of the manuscript.

Funding: This research received no external funding.

Acknowledgments: We thank USAII for elemental analysis, mass spectrometry, nuclear magnetic resonance tests and chromatography coupled to mass spectrometry tests; PAPIIT IN230020 for financial support and PAPIIT IN217613 for scholarships (CSNR, and ASB).

Conflicts of Interest: The authors declare no conflict of interest.

\section{References}

1. Ito, Y.N.; Katsuki, T. Asymmetric Catalysis of New Generation Chiral Metallosalen Complexes. Bull. Chem. Soc. Jpn. 1999, 72, 603-619. [CrossRef]

2. Naeimi, H.; Karshenas, A. Highly regioselective conversion of epoxides to $\beta$-hydroxy nitriles using metal(II) Schiff base complexes as new catalysts under mild conditions. Polyhedron 2013, 49, 234-238. [CrossRef]

3. Dalton, C.T.; Ryan, K.M.; Langan, I.J.; Coyne, É.J.; Gilheany, D.G. Asymmetric alkene epoxidation with chromium oxo salen complexes: Effect of $\pi$-rich and other types of additives. J. Mol. Catal. A Chem. 2002, 187, 179-187. [CrossRef]

4. Yang, H.; Zhang, L.; Su, W.; Yang, Q.; Li, C. Asymmetric ring-opening of epoxides on chiral Co(Salen) catalyst synthesized in SBA-16 through the "ship in a bottle" strategy. J. Catal. 2007, 248, 204-212. [CrossRef]

5. Bordoloi, A.; Amrute, A.P.; Halligudi, S.B. $[\mathrm{Ru}($ salen)(NO)] complex encapsulated in mesoporous SBA-16 as catalyst for hydrogenation of ketones. Catal. Commun. 2008, 10, 45-48. [CrossRef]

6. Chatterjee, D.; Bajaj, H.C.; Das, A.; Bhatt, K. First report on highly efficient alkene hydrogenation catalysed by $\mathrm{Ni}($ salen) complex encapsulated in zeolite. J. Mol. Cat. 1994, 92, L235-L238. [CrossRef]

7. Hamdan, H.; Navijanti, V.; Nur, H.; Muhid, M.N.M. Fe(III)-salen encapsulated Al-MCM-41 as a catalyst in the polymerisation of bisphenol-A. J. Solid State Sci. 2005, 7, 239-244. [CrossRef]

8. Ding, L.; Liang, S.; Zhang, J.; Ding, C.; Chen, Y.; Lü, X. $\mathrm{Cu}^{2+}$-templated self-assembly of an asymmetric Salen-Cu(II) complex and its application in catalytic polymerization of methyl methacrylate (MMA). Inorg. Chem. Commun. 2014, 44, 173-176. [CrossRef]

9. Butsch, K.; Günther, T.; Klein, A.; Stirnat, K.; Berkessel, A.; Neudörfl, J. Redox chemistry of copper complexes with various salen type ligands. Inorganica Chimi. Acta 2013, 394, 237-246. [CrossRef]

10. Pratt, R.C.; Stack, T.D.P. Mechanistic insights from reactions between copper(II)-phenoxyl complexes and substrates with activated C-H bonds. Inorg. Chem. 2005, 44, 2367-2375. [CrossRef]

11. Thomas, F. Ten years of a biomimetic approach to the copper(II) radical site of galactose oxidase. Eur. J. Inorg. Chem. 2007, 2379-2404. [CrossRef]

12. Mahapatra, P.; Drew, M.G.B.; Ghosh, A. Ni(II) Complex of $\mathrm{N}_{2} \mathrm{O}_{3}$ Donor Unsymmetrical Ligand and Its Use for the Synthesis of NiII-MnII Complexes of Diverse Nuclearity: Structures, Magnetic Properties, and Catalytic Oxidase Activities. Inorg. Chem. 2018, 57, 8338-8353. [CrossRef] [PubMed]

13. Kianfar, A.H.; Paliz, M.; Roushani, M.; Shamsipur, M. Synthesis, spectroscopy, electrochemistry and thermal study of vanadyl tridentate Schiff base complexes. Spectrochim Acta A 2011, 82, 44-48. [CrossRef] [PubMed] 
14. Santos, I.C.; Vilas-boas, M.; Piedade, M.F.M.; Freire, C.; Duarte, M.T.; Castro, B. De Electrochemical and $X$-ray studies of nickel (II) Schiff base complexes derived from salicylaldehyde. Structural effects of bridge substituents on the stabilisation of the +3 oxidation state. Polyhedron 2000, 19, 655-664. [CrossRef]

15. Shehata, E.E.; Masoud, M.S.; Khalil, E.A.; Abdel-Gaber, A.M. Synthesis, spectral and electrochemical studies of some Schiff base $\mathrm{N}_{2} \mathrm{O}_{2}$ complexes. J. Mol. Liq. 2014, 194, 149-158. [CrossRef]

16. Carradori, S.; De Monte, C.; D’Ascenzio, M.; Secci, D.; Celik, G.; Ceruso, M.; Vullo, D.; Scozzafava, A.; Supuran, C.T. Salen and tetrahydrosalen derivatives act as effective inhibitors of the tumor-associated carbonic anhydrase XII-A new scaffold for designing isoform-selective inhibitors. Bioorg. Med. Chem. Lett. 2013, 23, 6759-6763. [CrossRef]

17. Hang, Z.X.; Dong, B.; Wang, X.W. Synthesis, crystal structures, and antibacterial activity of zinc(II) complexes with bis-schiff bases. Synth. React. Inorg. Met. Org. Chem. 2012, 42, 1345-1350. [CrossRef]

18. Fasina, T.M.; Ogundele, O.; Ejiah, F.N.; Dueke-Eze, C.U. Biological Activity of Copper (II), Cobalt (II) and Nickel (II) Complexes of Schiff Base Derived from O-phenylenediamine and 5-bromosalicylaldehyde. Int. J. Biol. Chem. 2012, 6, 24-30. [CrossRef]

19. Woldemariam, G.A.; Mandal, S.S. Iron(III)-salen damages DNA and induces apoptosis in human cell via mitochondrial pathway. J. Inorg. Biochem. 2008, 102, 740-747. [CrossRef]

20. Ansari, K.I.; Grant, J.D.; Kasiri, S.; Woldemariam, G.; Shrestha, B.; Mandal, S.S. Manganese(III)-salens induce tumor selective apoptosis in human cells. J. Inorg. Biochem. 2009, 103, 818-826. [CrossRef]

21. Meshkini, A.; Yazdanparast, R. Chemosensitization of human leukemia K562 cells to taxol by a Vanadium-salen complex. Exp. Mol. Pathol. 2010, 89, 334-342. [CrossRef]

22. Immel, T.A.; Grützke, M.; Batroff, E.; Groth, U.; Huhn, T. Cytotoxic dinuclear titanium-salan complexes: Structural and biological characterization. J. Inorg. Biochem. 2012, 106, 68-75. [CrossRef] [PubMed]

23. Gravert, D.J.; Griffin, J.H. Specific DNA cleavage mediated by manganese complex [Salen Mn(III)]+. J. Org. Chem. 1993, 58, 820-822. [CrossRef]

24. Peng, B.; Zhou, W.H.; Yan, L.; Liu, H.W.; Zhu, L. DNA-binding and cleavage studies of chiral Mn(III) salen complexes. Transit. Metal. Chem. 2009, 34, 231-237. [CrossRef]

25. Bhattacharya, S.; Mandal, S.S. Ambient oxygen activating water soluble Cobalt-Salen complex for DNA cleavage. J. Chem. Soc. Chem. Commun. 1995, 2489-2490. [CrossRef]

26. Ali, A.; Kamra, M.; Bhan, A.; Mandal, S.S.; Bhattacharya, S. New Fe(III) and Co(II) salen complexes with pendant distamycins: Selective targeting of cancer cells by DNA damage and mitochondrial pathways. Dalton Trans. 2016, 45, 9345-9353. [CrossRef]

27. Muller, J.G.; Paikoff, S.J.; Rokita, S.E.; Burrows, C.J. DNA modification promoted by water-soluble nickel(II) salen complexes: A switch to DNA alkylation. J. Inorg. Biochem. 1994, 54, 199-206. [CrossRef]

28. Mariappan, M.; Suenaga, M.; Mukhopadhyay, A.; Maiya, B.G. Synthesis, structure, DNA binding and photonuclease activity of a nickel(II) complex with a N,N'-Bis(salicylidene)-9-(3,4-diaminophenyl) acridine ligand. Inorg. Chim. Acta 2012, 390, 95-104. [CrossRef]

29. Zhou, C.Q.; Liao, T.C.; Li, Z.Q.; Gonzalez-Garcia, J.; Reynolds, M.; Zou, M.; Vilar, R. Dinickel-salphen complexes as binders of human telomeric dimeric G-quadruplexes. Chem. Eur. J. 2017, 23, 4713-4722. [CrossRef]

30. Reed, J.E.; Arnal, A.A.; Neidle, S.; Vilar, R. Stabilization of G-quadruplex DNA and inhibition of telomerase activity by square-planar nickel(II) complexes. J. Am. Chem. Soc. 2006, 128, 5992-5993. [CrossRef]

31. Mukherjee, P.; Biswas, C.; Drew, M.G.B.; Ghosh, A. Structural variations in Ni(II) complexes of salen type di-Schiff base ligands. Polyhedron 2007, 26, 3121-3128. [CrossRef]

32. Ghaemi, A.; Fayyazi, K.; Keyvani, B.; Ng, S.W.; Tiekink, E.R.T. \{2,2'-[o-Phenylenebis(nitrilomethanylylidene)] diphenolato- $44 \mathrm{O}, \mathrm{N}_{1} \mathrm{~N}^{\prime}, \mathrm{O}^{\prime}$ \}nickel(II) monohydrate. Acta Crystallogr. Sect. E Struct. Rep. Online 2011, E67, m1481-m1482. [CrossRef]

33. Siegler, M.A.; Lutz, M. Ni(salen): A system that forms many solvates with interacting Ni atoms. Cryst. Growth Des. 2009, 9, 1194-1200. [CrossRef]

34. Choudhary, A.; Das, B.; Ray, S. Enhanced catalytic activity and magnetization of encapsulated nickel Schiff-base complexes in zeolite-Y: A correlation with the adopted non-planar geometry. Dalton Trans. 2016, 45, 18967-18976. [CrossRef]

35. Xu, Y.; Xue, L.; Wang, Z.G. Synthesis, X-ray crystal structures, and antibacterial activities of Schiff base nickel(II) complexes with similar tetradentate Schiff bases. Russ. J. Coord. Chem. 2017, 43, 314-319. [CrossRef] 
36. Lamour, E.; Routier, S.; Bernier, J.L.; Catteau, J.P.; Bailly, C.; Vezin, H. Oxidation of Cu(II) to Cu(III), free radical production, and DNA cleavage by hydroxy-salen-copper complexes. Isomeric effects studied by ESR and electrochemistry. J. Am. Chem. Soc. 1999, 121, 1862-1869. [CrossRef]

37. Aein Jamshid, K.; Asadi, M.; Hossein Kianfar, A. Synthesis, characterization and thermal studies of dinuclear adducts of diorganotin(IV) dichlorides with nickel(II) Schiff-base complexes in chloroform. J. Coord. Chem. 2009, 62, 1187-1198. [CrossRef]

38. Biradar, N.S.; Karajagi, G.V.; Roddabasanagoudar, V.L.; Aminabhavi, T.M. Geometrical transformations around nickel(ii) with silicon(iv) tetrachloride. Synth. React. Inorg. Met.-Org. Chem. 1984, 14, 773-783. [CrossRef]

39. Naeimi, H.; Moradian, M. Efficient synthesis and characterization of some novel nitro-schiff bases and their complexes of nickel(II) and copper(II). J. Chem. 2013, 2013. [CrossRef]

40. Eltayeb, N.E.; Teoh, S.G.; Chantrapromma, S.; Fun, H.K.; Ibrahim, K. 4,4'-Dimethoxy-2,2'-[1,2-phenylenebis(nitrilomethylidyne)] diphenol. Acta Crystallogr. Sect. E Struct. Rep. Online 2007, 63. [CrossRef]

41. Wang, J.; Bei, F.; Xu, X.; Yang, X.; Wang, X. Crystal structure and characterization of 1, 2-N, N-disallicydene-phenylamineato nickel (II) complex. J. Chem. Crystallogr. 2003, 33, 845-849. [CrossRef]

42. Elerman, Y.; Elmali, A.; Kabak, M.; Aydin, M.; Peder, M. Crystal structure of bis-N,N'-p-chloro-salicylideneamine-1,2.diaaminobenzene. J. Chem. Cryst. 1994, 24, $603-606$. [CrossRef]

43. Batley, G.; Graddon, D. Nickel(II) hydrosalicylamide complexes. Aust. J. Chem. 1967, 20, 1749. [CrossRef]

44. Kondo, M.; Nabari, K.; Horiba, T.; Irie, Y.; Shimizu, Y.; Fuwa, Y. Synthesis and crystal structure of [Ni\{bis(2,5-dihydroxysalicylidene)ethylenediaminato\}]: A hydrogen bonded assembly of Ni (II)-salen complex. Inorga Chem Commun 2003, 6, 154-156. [CrossRef]

45. Asadi, M.; Jamshid, K.A.; Kyanfar, A.H. Synthesis, characterization and equilibrium study of the dinuclear adducts formation between nickel(II) Salen-type complexes with diorganotin(IV) dichlorides in chloroform. Inorganica Chimica Acta 2007, 360, 1725-1730. [CrossRef]

46. Oxford Diffraction Ltd. Available online: https://www.rigaku.com/products/smc/crysalis (accessed on 17 July 2019).

47. Clark, R.C.; Reid, J.S. The analytical calculation of absorption in multifaceted crystals. Acta Crystallogr. A 1995, 51, 887-897. [CrossRef]

48. Sheldrick, G.M. SHELXT-Integrated space-group and crystal-structure determination. Acta Crystallogr. A Found. Crystallogr. 2015, 71, 3-8. [CrossRef]

49. Sheldrick, G.M. Crystal structure refinement with SHELXL. Acta Crystallogr. C 2015, C71, 3-8. [CrossRef]

50. Farrugia, L.J. WinGX and ORTEP for Windows: An update. J. Appl. Crystallogr. 2012, 45, 849-854. [CrossRef]

51. Spek, A.L. PLATON SQUEEZE: A tool for the calculation of the disordered solvent contribution to the calculated structure factors. Acta Crystallogr. Sect. C Struct. Chem. 2015, C71, 9-18. [CrossRef]

52. Garg, B.S.; Nandan Kumar, D. Spectral studies of complexes of nickel(II) with tetradentate schiff bases having N2O2 donor groups. Spectrochim Acta A Mol. Biomol. Spectrosc. 2003, 59, 229-234. [CrossRef]

53. Lever, A.B.P. Inorganic Electronic Spectroscopy, 2nd ed.; Elsevier: New York, NY, USA, 1984.

54. Maki, G. Ligand field theory of Ni (II) complexes. I. Electronic energies and singlet ground-state conditions of $\mathrm{Ni}$ (II) complexes of different symmetries. J. Chem. Phys. 1958, 28, 651-662. [CrossRef]

55. Kianfar, A.H.; Dostani, M.; Mahmood, W.A.K. An unprecedented DDQ-nickel(II)Salen complex interaction and X-ray crystal structure of nickel(II)Salen.DDH co-crystal. Polyhedron 2015, 85, 488-492. [CrossRef]

56. Spackman, M.A.; Jayatilaka, D. Hirshfeld surface analysis. Cryst. Eng. Comm. 2009, 11, 19-32. [CrossRef]

57. Wolff, S.K.; Grimwood, D.J.; McKinnon, J.J.; Jayatilaka, D.; Spackman, M.A. Available online: http: //hirshfeldsurface.net/CrystalExplorer (accessed on 17 July 2019).

58. Isse, A.A.; Gennaro, A.; Vianello, E. Electrochemical reduction of Schiff base ligands H2salen and H2salophen. Electrochim. Acta 1997, 42, 2065-2071. [CrossRef]

59. Pooyan, M.; Ghaffari, A.; Behzad, M.; Amiri Rudbari, H.; Bruno, G. Tetradentate N $2 \mathrm{O} 2$ type Nickel(II) Schiff base complexes derived from meso -1,2-diphenyle-1,2-ethylenediamine: Synthesis, characterization, crystal structures, electrochemistry, and catalytic studies. J. Coord. Chem. 2013, 66, 4255-4267. [CrossRef]

60. Freire, C. Spectroscopic characterisation of electrogenerated nickel(III) species. Complexes with $\mathrm{N}_{2} \mathrm{O}_{2}$ Schiff-base ligands derived from salicylaldehyde. J. Chem. Soc. Dalton Trans. 1998, 1491-1498. [CrossRef] 
61. Jäger, E.G.; Schuhmann, K.; Görls, H. Syntheses, characterization, redox behavior and Lewis acidity of chiral nickel(II) and copper(II) Schiff base complexes. Inorg. Chim. Acta 1997, 255, 295-305. [CrossRef]

62. Zolezzi, S.; Spodine, E.; Decinti, A. Electrochemical studies of copper(II) complexes with Schiff-base ligands. Polyhedron 2002, 21, 55-59. [CrossRef]

63. Kianfar, A.H.; Sobhani, V.; Dostani, M.; Shamsipur, M.; Roushani, M. Synthesis, spectroscopy, electrochemistry and thermal study of vanadyl unsymmetrical Schiff base complexes. Inorg. Chim. Acta 2011, 365, 108-112. [CrossRef]

(C) 2020 by the authors. Licensee MDPI, Basel, Switzerland. This article is an open access article distributed under the terms and conditions of the Creative Commons Attribution (CC BY) license (http://creativecommons.org/licenses/by/4.0/). 